OPEN ACCESS

Edited by:

Jianxun Ding,

Chinese Academy of Sciences, China

Reviewed by:

Jindan Wu,

Zhejiang Sci-Tech University, China

Shuaishuai Yuan,

Qingdao University of Science and

Technology, China

*Correspondence:

Xiaorong Lan

xiaoronglancdm@163.com

Fei Deng

dengfei_here@163.com

Specialty section:

This article was submitted to

Biomaterials,

a section of the journal Frontiers in Bioengineering and

Biotechnology

Received: 02 November 2021

Accepted: 22 November 2021

Published: 07 December 2021

Citation:

He Z, Yang X, Wang N, Mu L, Pan J,

Lan X, Li H and Deng F (2021) Anti-

Biofouling Polymers with Special

Surface Wettability for

Biomedical Applications.

Front. Bioeng. Biotechnol. 9:807357.

doi: $10.3389 /$ fbioe. 2021.807357

\section{Anti-Biofouling Polymers with Special Surface Wettability for Biomedical Applications}

\author{
Zhoukun $\mathrm{He}^{1}$, Xiaochen Yang ${ }^{1,2}$, Na Wang ${ }^{1,2}$, Linpeng $\mathrm{Mu}^{1,2}$, Jinyuan Pan ${ }^{1,2}$, Xiaorong Lan $^{3 *}$, \\ Hongmei $\mathrm{Li}^{4}$ and Fei Deng ${ }^{5,6 *}$ \\ ${ }^{1}$ Institute for Advanced Study, Research Center of Composites and Surface and Interface Engineering, Chengdu \\ University, Chengdu, China, ${ }^{2}$ School of Mechanical Engineering, Chengdu University, Chengdu, China, ${ }^{3}$ National \\ Engineering Research Center for Biomaterials, Sichuan University, Chengdu, China, ${ }^{4}$ School of Food and Biological \\ Engineering, Chengdu University, Chengdu, China, ${ }^{5}$ Department of Nephrology, Jinniu Hospital of Sichuan Provincial \\ People's Hospital and Chengdu Jinniu District People's Hospital, Chengdu, China, ${ }^{6}$ Department of Nephrology, Sichuan \\ Academy of Medical Sciences and Sichuan Provincial People's Hospital, University of Electronic Science and \\ Technology of China, Chengdu, China
}

The use of anti-biofouling polymers has widespread potential for counteracting marine, medical, and industrial biofouling. The anti-biofouling action is usually related to the degree of surface wettability. This review is focusing on antibiofouling polymers with special surface wettability, and it will provide a new perspective to promote the development of anti-biofouling polymers for biomedical applications. Firstly, current anti-biofouling strategies are discussed followed by a comprehensive review of anti-biofouling polymers with specific types of surface wettability, including superhydrophilicity, hydrophilicity, and hydrophobicity. We then summarize the applications of anti-biofouling polymers with specific surface wettability in typical biomedical fields both in vivo and in vitro, such as cardiology, ophthalmology, and nephrology. Finally, the challenges and directions of the development of anti-biofouling polymers with special surface wettability are discussed. It is helpful for future researchers to choose suitable anti-biofouling polymers with special surface wettability for specific biomedical applications.

Keywords: anti-biofouling, antifouling, superhydrophilic, hydrophilic, hydrophobic

\begin{abstract}
Abbreviations: BSA, bovine serum albumin; CLs, contact lens; E. coli, escherichia coli; FITC-BSA, fluorescein isothiocyanate conjugate-bovine serum albumin; FITC-HSA, fluorescein isothiocyanate conjugate-human serum albumin; IgG, immunoglobulin G; IOL, intraocular lens; MI-dPG, mussel-inspired dendritic polyglycerol; MPDSAH, (3-(methacryloylamino)propyl)dimethyl (3-sulfopropyl) ammonium hydroxide inner salt; PAA, poly(acrylic acid); PCBAA, poly(carboxybetaine acrylamide); PCBMA, poly(carboxybetaine methacrylate); PCL, polycaprolactide; PDMS, poly(dimethyl siloxane); PEG, poly(ethylene glycol); PEGDA, poly(ethylene glycol) diacrylate; PEO, poly(ethylene oxide); PES, poly(ether sulfone); PHEMA, poly(2hydroxyethyl methacrylate); PLA, poly(lactic acid); PMMA, poly(methyl methacrylate); PPGL, homopolymer grafts from a-tert-butoxy- $\omega$-vinylbenzyl-polyglycidol; PSBMA, poly(sulfobetaine methacrylate); PSF, polysulfone; PU, polyurethanes; PVA, poly(vinyl alcohol); PVP, poly(N-vinyl pyrrolidone); S. aureus, staphylococcus aureus; SEM, scanning electron microscopy; S. epidermidis, staphylococcus epidermidis; WCA, water contact angle.
\end{abstract}




\section{INTRODUCTION}

The first known documentation of fouling is a papyrus dating from 412 BCE (1). To date, many kinds of fouling, such as dust, ice, crude oil, barnacles, bacteria, and blood, have been described and researched. Fouling has serious impacts on human life, as it degrades material surfaces, increases drag resistance in ships, and promotes infection in hospitals (1, (Almeida et al., 2007; He et al., 2021)). Our previous review defined four categories of foulant, namely, organic, inorganic, biofouling, and composite fouling (He et al., 2021). Biofouling is a persistent and widespread problem, the consequence of the aggregation of undesirable and often pathogenic organisms on surfaces, comprising biofilm produced by microorganisms and macroscale biofouling (macrofouling) resulting from foulants such as bacteria, cells, and proteins. As shown in Figure 1, biofouling usually begins with a surface film formed by organic molecules, to which different foulants attach, resulting in mixed communities that may undergo long-term changes over long periods of time (Rosenhahn et al., 2010). The presence of biofouling has significant impacts in various fields, including ships' hulls, water pipes, biosensors, filters, and in the biomedical field where it contaminates applications such as surgical products, sutures, and dressings (Liu et al., 2020a).

Biofouling has been divided into three categories: marine, industrial, and medical (Callow and Callow, 2011; Bixler et al., 2014). In marine and freshwater environments, biofouling involves the undesirable attachment of organisms to artificial surfaces, such as ceramic, metal, or plastic (Dobretsov et al., 2013; Mieszkin et al., 2013; Hu et al., 2020). In the medical field, microorganisms may attach to devices and biosensors, resulting in the infection of patients (Jorge et al., 2012; Ammons and Copié, 2013; Leslie et al., 2014; Gaw et al., 2017). In industrial situations, microorganisms may feed and proliferate using nutrients in membranes, eventually blocking the pores (Bixler and Bhushan, 2012). Biofouling of microbes and viruses to surfaces, especially for medical biofouling, still remains an urgent problem to be solved owing to their crucial roles in medical implants, CLs, catheters, hemodialyzers, biosensors, and respirators (Jorge et al., 2012; Ammons and Copié, 2013; Leslie et al., 2014; Gaw et al., 2017). For example, the COVID-19 emergency lasted nearly 2 years but there is still no sign of it disappearing. The COVID-19 virus as a new kind of biofoulant is probably inhibited to fouling the materials with an antibiofouling ability. Suhas S. Joshi and coauthors reported that fullerene-coated anti-biofouling surfaces could be a possible solution to decrease the adhesion of the COVID-19 virus on the surface, as they will be hydrophobic and toxic to the virus envelope (Siddiquie et al., 2020a).

The use of chemical coatings based on biocides or enzymes is the initial strategy in the prevention of fouling (Lejars et al., 2012). Although these strategies are effective in fouling prevention, they may be toxic to animals and plants in terrestrial and marine

${ }^{1}$ http://corrosion-doctors.org/Seawater/Fouling.htm ${ }^{1}$ http://corrosion-doctors.org/Seawater/Fouling.htm environments if there are some harmful materials in the coatings (Yebra et al., 2004), such as organotin, copper, etc. Because of this, there are restrictions and even prohibitions on the use of such materials. A following developed strategy is the use of selfpolishing coatings. These rely on the hydrolysis of side-chains or degradation of the main polymer chain (Zhang and Chiao, 2015; Yang et al., 2020). Nevertheless, these coatings still have adverse environmental. Thus, the traditionally used chemical and self-polishing coatings are not adequate for the complex conditions present in the world today (Zhang et al., 2016). In biomedical situations, it has been proposed to use materials that either prevent the attachment of microorganisms to devices or destroy them in the vicinity of the device. These materials include coatings that repel or prevent attachment or kill the microorganisms in the vicinity. A variety of polymers have been developed to counteract or reduce biofilm (Carr et al., 2011; Jorge et al., 2012; He et al., 2021), including: 1) cationic or peptide-mimicking polymers, or composites that can retain and release bioactive compounds; and 2) systems that can prevent microbial attachment by either physical or chemical means. Antifouling and antimicrobial coating may be differentiated by ability of the former to repel microbes or modify the structure of biofilm, while the latter have either bacteriostatic or bactericidal activities. Antifouling coatings use steric repulsion or nanoscale rough topography to prevent microbial attachment, while antimicrobial materials interact directly, resulting in microbial death through physical contact or the release of bactericidal compounds (Zheng et al., 2021). In general, environmentally safe and non-toxic antifouling polymer coating materials thus require specific attributes of surface chemical compositions and physical structures, which both significantly affect the surface wettability that can be quantified as the water droplets contact angle (WCA, $0-180^{\circ}$ ) on the surface (Zhu et al., 2012; He et al., 2013; Tian et al., 2014; Yu et al., 2015; Kuang et al., 2016; Martin et al., 2017; Yu et al., 2018; Li et al., 2019a; Zhu et al., 2019). As defined by Young's equation (Young, 1805), the Wenzel model (Wenzel, 1936), and the Cassie-Baxter model (Cassie and Baxter, 1944), the surface wettability can be described as superhydrophilic $\left(\mathrm{WCA}<10^{\circ}\right.$ ), hydrophilic (WCA $<90^{\circ}$ ), hydrophobic (WCA $\geq 90^{\circ}$ ), and superhydrophobic (WCA $\geq 150^{\circ}$ ), as shown in Figure 2 .

Since the surface wettability and antifouling action of coatings are dependent on the properties, both chemical compositions and physical structures, of the surfaces (Maan et al., 2020), there should be some relationship between the surface wettability and antifouling ability of materials. Actually, many organisms with antifouling ability such as Lotus Leaf, Rice Leaf, and Shark Skin have a natural special surface wettability. After the design principle of materials with special surface wettability has been proposed by Lei Jiang et al. (Su et al., 2016), alterations in surface wettability allow the fine-tuning of bionic antifouling coatings and such techniques have attracted much attention over the past decade (He et al., 2021). The fluoro- and silicone-based hydrophobic polymers used in traditional antifouling materials reduce the attachment of the fouling substances to the surface (Lejars et al., 2012; Dobretsov and Thomason, 2011; Liang et al., 2020; Carl et al., 2012). Together with the chemical composition 


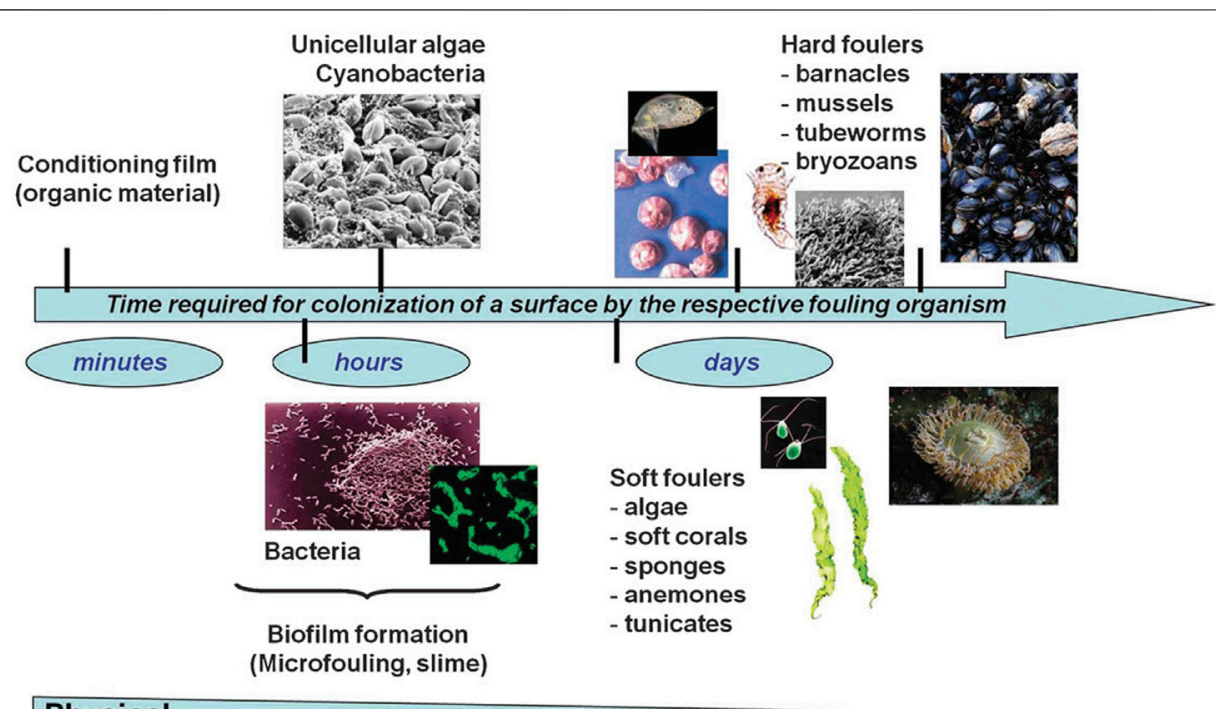

Biological

FIGURE 1 | Surface colonization by a fouling organism. Reprinted with permission from Ref. (Rosenhahn et al., 2010). Copyright 2010, Royal Society of Chemistry.

of the material, physical properties including the "Lotus Leaf," "Rice Leaf," and "Shark Skin" effects also influence the antifouling action (Zhang et al., 2016; Zhao and Liu, 2016; Shi et al., 2015; Lee and Yong, 2015; Roach et al., 2008; Pan et al., 2019; Jiang et al., 2015; Ball, 1999; Pu et al., 2016; Azemar et al., 2015; Kang et al., 2013; Bixler and Bhushan, 2013; Zhu et al., 2010; Bixler and Bhushan, 2014; Wu et al., 2011; Lee et al., 2013; Xia and Jiang, 2008). Engineered micro-topographical structures together with specific chemicals are commonly used for bionic implementation (Scardino and de Nys, 2011; Zarghami et al., 2019). Jie Zheng and coauthors have reviewed hydrophilic non-fouling materials and emphasized the importance of using strongly hydrated groups with optimal physical attributes on the material surface, concluding that, together with methods for coating surfaces, are critical for the development of stable and successful nonfouling materials for use in biomedical devices and applications (Chen et al., 2010). As shown in Figure 3, we have comprehensively reviewed the antifouling strategies for the four types of fouling according to different super-phobic surfaces, namely, superhydrophobicity in air (He et al., 2011; Martin and Bhushan, 2017), superoleophobicity in air (Chen et al., 2019; Li et al., 2020), superhemophobicity in air (Movafaghi et al., 2017; Galante et al., 2020), and underwater superoleophobicity (Du et al., 2017; Su et al., 2018).

In this review, we will focus on the anti-biofouling strategies, because the removal of fouling resulting from the deposition of organic or inorganic material is usually easier than eliminating biofouling. Superhydrophobic or superoleophobic surfaces are often able to prevent and release inorganic fouling, while superoleophobic surfaces or surfaces with underwater superoleophobicity are suitable for organic contaminants. Biofouling, however, usually involves a variety of foulants, and the solution is not simple. The most effective method, in terms of both cost and efficacy, is the use of surface wettability to counteract the attachment of foulants. Actually, an antibiofouling surface can be achieved by tuning its surface wettability (Krishnan et al., 2008; He et al., 2021). For instance, anti-biofouling measures directed against bacteria

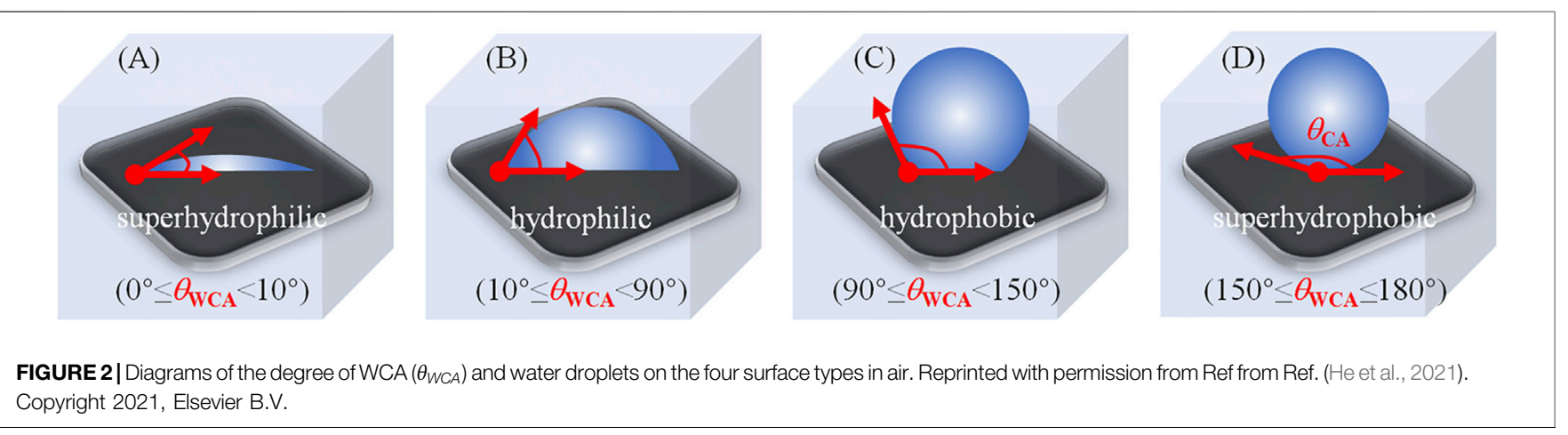




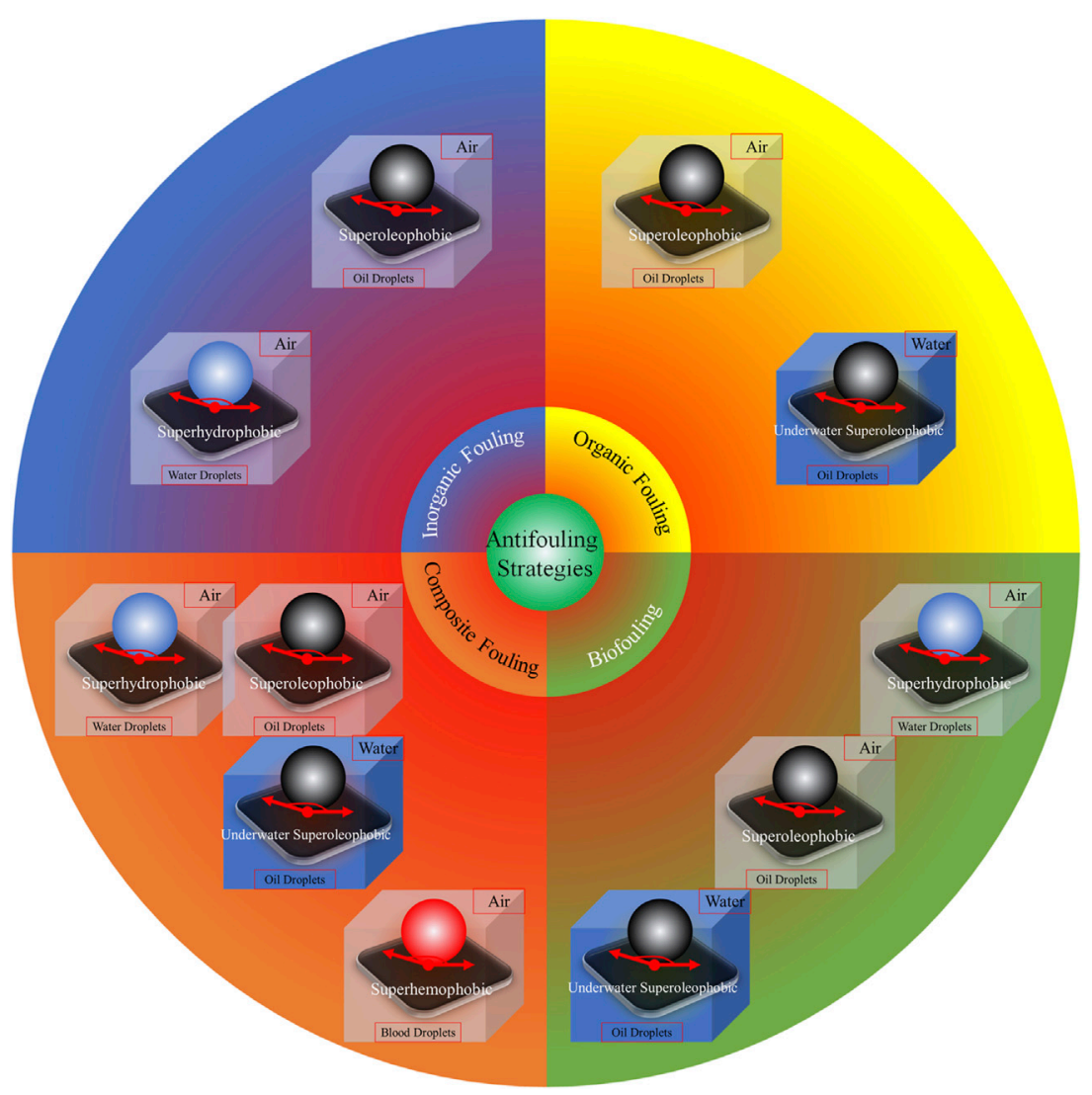

FIGURE 3 | Antifouling strategies based on various super-phobic surfaces. Reprinted with permission from Ref. (He et al., 2021). Copyright 2021, Elsevier B.V.

rely on hydrophilic or superhydrophobic effects (Liu et al., 2020b). In addition, surfaces with superhydrophobicity, usually containing a layer of air that blocks contact between the foulant and the surface (Simovich et al., 2020), are effective against fouling, as shown in Figure 3.

Biofouling extensively exists in biomedical applications both in vivo and in vitro, such as cardiology, ophthalmology, nephrology, and various surgical equipment. Bacteria, cells, and proteins usually adhere to and forming dense collagenous capsule around the biomedical implants, which would induce inflammatory responses, and may give rise to infection and/or implant rejection (Chan et al., 2020). Thus, in view of the necessity for anti-biofouling in biomedical applications, we will focus on the anti-biofouling strategies based on polymers with special surface wettability such as superhydrophilicity, hydrophilicity and hydrophobicity but excluding superhydrophobicity which can be found in our previous review (He et al., 2021). Meanwhile, we just focus on the biomedical applications in cardiology, ophthalmology, and nephrology. Moreover, biofoulants mentioned in this review are focused on the usual bacteria, cells, and proteins. Although there are some reviews about antifouling polymers (Lejars et al., 2012; Wu et al., 2019; Maan et al., 2020), our review is focusing on anti-biofouling polymers with special surface wettability, and it will provide a new perspective to promote the development of anti-biofouling polymers. Meanwhile, the anti-biofouling strategies reviewed in this manuscript will offer help for future researchers to choose suitable polymers for specific antibiofouling applications.

\section{ANTI-BIOFOULING POLYMERS WITH SPECIAL SURFACE WETTABILITY}

Anti-biofouling polymers are attractive as they can avoid the introduction of drugs to achieve anti-biofouling but their efficacy is determined by the polymer and foulant species (Francolini et al., 2015). As summarized in Table 1, numerous proposals with various surface wettability have been reported to generate antibiofouling ability. The various types of polymers and biofoulants are also listed in Table 1, which clearly reveals the relationship between the polymers and foulants (bacteria, cells, proteins, etc.).

\section{Superhydrophilicity}

Surfaces that prevent both microbial attachment and non-specific protein adsorption are required in the biomedical sphere. These should be hydrophilic as the polymer surface should bind water in preference to microorganisms. Wetting is thus an important consideration (Chen et al., 2010). According to these criteria, a number of anti-biofouling polymers have been developed that 
TABLE 1 | A summary of polymers with different surface wettability and the relevant types of foulants for anti-biofouling applications (sorted in alphabetical order of the description of the typical polymers for each special surface wettability).

\begin{tabular}{|c|c|c|c|c|}
\hline $\begin{array}{l}\text { Strategy based } \\
\text { on } \\
\text { surface } \\
\text { wettability }\end{array}$ & WCA( $\left(^{\circ}\right.$ & Typical polymers & Foulants & Ref \\
\hline \multirow{5}{*}{$\begin{array}{l}\text { Superhydro- } \\
\text { philicity }\end{array}$} & 0 & Ml-dPG & (a) Bacteria: E. coli, S. aureus & Li et al. (2019b) \\
\hline & $<5$ & PCBAA & $\begin{array}{l}\text { (a) Cells: GLC-82 cells } \\
\text { (b) Proteins: FITC-BSA, FITC-HSA } \\
\text { (c) Blood: Blood cells, Blood proteins }\end{array}$ & Xu et al. (2017) \\
\hline & 0 & PPGL & (a) Proteins: Anti-BSA, Anti-myoglobin & Gam-Derouich et al. (2011) \\
\hline & 6 & Sulfobetaine silane & $\begin{array}{l}\text { (a) Bacteria: P. aeruginosa, S. } \\
\text { epidermidis } \\
\text { (b) Proteins: BSA, Mucin, Lysozyme, } \\
\text { Liposomes }\end{array}$ & Yeh et al. (2014) \\
\hline & 10 & Zwitterionic bottlebrush polymers & $\begin{array}{l}\text { (a) Bacteria: E. coli } \\
\text { (b) Proteins: BSA, Lysozyme, } \\
\beta \text {-Lactoglobulin }\end{array}$ & Xia et al. (2019) \\
\hline \multirow[t]{10}{*}{ Hydrophilicity } & 28 & PAA & $\begin{array}{l}\text { (a) Proteins: BSA } \\
\text { (b) Cells: L929 cells } \\
\text { (c) Blood: Blood erythrocytes }\end{array}$ & Lei et al. (2021) \\
\hline & 27 & PCBAA & $\begin{array}{l}\text { (a) Bacteria: E. coli, S. aureus } \\
\text { (b) Cells: L929 } \\
\text { (c) Protein: BSA, HRP-conjugated } \\
\text { anti-IgG }\end{array}$ & Wang et al. (2018); Zhang et al. (2021a) \\
\hline & $26-74$ & PEG & $\begin{array}{l}\text { (a) Bacteria: S. epidermidis, S. aureus, } \\
\text { P. aeruginosa } \\
\text { (b) Cells: Human corneal epithelial cells } \\
\text { (c) Proteins: BSA, Lysozyme } \\
\text { (d) Fungi: C. albicans, F. solani }\end{array}$ & Cheng et al. (2015); Wang and He, (2019) \\
\hline & 72 & Poloxamers 338 & (a) Bacteria: E. coli & Stirpe et al. (2020) \\
\hline & 17 & $\begin{array}{l}\text { Poly(carboxylbetaine-co-dopamine } \\
\text { methacrylamide) copolymer }\end{array}$ & $\begin{array}{l}\text { (a) Bacteria: E. coli, P. aeruginosa, S. } \\
\text { aureus } \\
\text { (b) Fungi: C. albicans }\end{array}$ & Liu et al. (2020c) \\
\hline & 56 & Poly (citric acid) & (a) Proteins: BSA & Abidin et al. (2016) \\
\hline & 36 & Poly(p-phenylene terephthalamide) & $\begin{array}{l}\text { (a) Bacteria: E. coli } \\
\text { (b) Proteins: BSA }\end{array}$ & Chen et al. (2018) \\
\hline & $12-38$ & PSBMA & $\begin{array}{l}\text { (a) Bacteria: E. coli, S. epidermidis } \\
\text { (b) Cells: Human MG63 osteoblast, } \\
\text { HT1080 fibroblast, L929 } \\
\text { (c) Blood: Plasma protein, Blood } \\
\text { platelets, Blood erythrocytes, Blood } \\
\text { leukocytes }\end{array}$ & $\begin{array}{l}\text { Chen et al. (2012); Sin et al. (2014); Li et al. (2017); Zhang } \\
\text { et al. (2021b) }\end{array}$ \\
\hline & 63 & PVA & $\begin{array}{l}\text { (a) Proteins: BSA } \\
\text { (b) Cells: L929 cells }\end{array}$ & Lan et al. (2021) \\
\hline & $20-60$ & PVP & $\begin{array}{l}\text { (a) Bacteria: S. aureus, E. coli } \\
\text { (b) Cells: L929 cells } \\
\text { (c) Proteins: FITC-BSA, Fibrinogen, IgG, } \\
\text { Lysozyme } \\
\text { (d) Blood: Platelets }\end{array}$ & $\begin{array}{l}\text { Telford et al. (2010); Ran et al. (2011); Wu et al. (2012); } \\
\text { Jiang et al. (2013); Liu et al. (2013); Zhu et al. (2017) }\end{array}$ \\
\hline
\end{tabular}

(Continued on following page) 
TABLE 1 | (Continued) A summary of polymers with different surface wettability and the relevant types of foulants for anti-biofouling applications (sorted in alphabetical order of the description of the typical polymers for each special surface wettability).

\begin{tabular}{|c|c|c|c|c|}
\hline $\begin{array}{l}\text { Strategy based } \\
\text { on } \\
\text { surface } \\
\text { wettability }\end{array}$ & WCA $\left({ }^{\circ}\right)$ & Typical polymers & Foulants & Ref \\
\hline & $\begin{array}{c}85 \\
25-80\end{array}$ & $\begin{array}{l}\text { Segmented PU with }-\mathrm{SO}_{3} \mathrm{H} \\
\text { Others }\end{array}$ & $\begin{array}{l}\text { (a) Bacteria: S. epidermidis } \\
\text { (a) Bacteria: S. aureus, E. coli } \\
\text { (b) Cells: L929 cells, Bovine aortic } \\
\text { endothelial cells } \\
\text { (c) Proteins: BSA, Fibrinogen, Lysozyme } \\
\text { (d) Blood: Platelet-rich plasma, Platelet- } \\
\text { poor plasma }\end{array}$ & $\begin{array}{l}\text { Francolini et al. (2012) } \\
\text { Huang et al. (2011); Seo et al. (2011); Chen et al. (2014); } \\
\text { Li et al. (2014); Xie et al. (2015); Yin et al. (2015); Wang } \\
\text { et al. (2016); Valencia et al. (2018); Xie et al. (2018); Ji } \\
\text { et al. (2019); Ye et al. (2019) }\end{array}$ \\
\hline Hydrophobicity & $\begin{array}{c}125 \\
100-147 \\
101 \\
106\end{array}$ & $\begin{array}{l}\text { 2-perfluorooctylethyl methacrylate } \\
\text { PDMS, PU, silicone oil } \\
\text { Poly(siloxane-urethane) } \\
\text { Others }\end{array}$ & $\begin{array}{l}\text { (a) Proteins: FITC-BSA, Fibrinogen } \\
\text { (a) Bacteria: E. coli } \\
\text { (a) Proteins: BSA. } \\
\text { (a) Bacteria: S. aureus, E. coli } \\
\text { (b) Proteins: BSA, Lysozyme }\end{array}$ & $\begin{array}{l}\text { Wang et al. (2015) } \\
\text { Siddiquie et al. (2020b) } \\
\text { Santiago et al. (2016) } \\
\text { Kim et al. (2016); Wang et al. (2017) }\end{array}$ \\
\hline
\end{tabular}

effectively prevent the adhesion of proteins, cells, and bacteria. These include hydrophilic polymers (Epstein et al., 2012; Keefe et al., 2012; Chen et al., 2015a; Mohan et al., 2015; Zhu et al., 2015; Guo et al., 2019; Jiang et al., 2020), e.g., PEG, PEGylated polymers, PHEMA, polysaccharides, and zwitterionic polymers (Carr et al., 2011; Chen et al., 2012; Sin et al., 2014; He et al., 2016; Kang et al., 2016; Wang et al., 2018; He et al., 2019; Liu et al., 2020c; Erathodiyil et al., 2020; Su et al., 2020; Zhang et al., 2020; Zhang et al., 2021a; Zhang et al., 2021b; Zhou et al., 2021), e.g., PSBMA, PCBMA, and PCBAA. Although these polymers differ in their structures and chemistry, they are all able to bind strongly to water, resulting in the presence of a layer of water that reduces interaction and attachment between the surface and the foulant. Effective surface hydration is achieved through hydrogen bonding in the case of hydrophilic polymers, and ionic solvation in the case of zwitterionic materials (Liu et al., 2020a). In addition, some papers have been published on the synthesis and application of polyglycidol and its derivatives with various morphologies. For example, the PPGL with a WCA near zero showed a superhydrophilic character and good antibiofouling ability tested in anti-BSA and anti-myoglobin experiments (Gam-Derouich et al., 2011).

Superhydrophilic anti-biofouling zwitterionic polymers show great potential for biomedical applications (Chan et al., 2020; Xu et al., 2017; Xia et al., 2019). Rongxin Su and coauthors reported an anti-biofouling three-block polymer with zwitterionic chains on the bottlebrush polymers that showed high stability in highsaline solutions and over an extensive $\mathrm{pH}$ range (Xia et al., 2019). The anti-biofouling properties benefited from a low WCA near $10^{\circ}$ as demonstrated by serum albumin and lysozyme adsorption with ultralow fouling properties of lower than $0.2 \mathrm{ng} \mathrm{cm}^{-2}$ (Xia et al., 2019). Jackie Y. Ying and coauthors produced a novel superhydrophilic anti-biofouling, biocompatible hydrogel formed by the crosslinking of polymers with calcium and monomers of methacryloyl-L-lysine (MLL), a zwitterionic amino acid (Chan et al., 2020). The resultant hydrogel containing $30 \%$ MLL was found to be strongly porous with a high degree of water encapsulation. The WCA on a glass slide with hydrogel coating decreased to $7.6^{\circ}$ and the superhydrophilic hydrogel was effective in preventing bacterial, cell, and protein adhesion. The anti-biofouling hydrogel did not form capsules when subcutaneously implanted in mice over 2 months (Chan et al., 2020). Lei Zhang and coauthors reported an efficient and simple strategy (Figure 4A) to modify hydrophobic electrospun meshes with zwitterionic PCBAA hydrogels to obtain superhydrophilic anti-biofouling meshes with WCAs of less than $5^{\circ}$ (Figures 4B,C) (Xu et al., 2017). The coated superhydrophilic mesh resisted attachment of FITC-BSA, FITC-HSA proteins, and GLC-82 cells (Figures 4D-4K). Furthermore, the hydrogel structure retained its stability under physiological conditions for a minimum of 3 months. This report demonstrates an effective technique for modulating hydrophilic surfaces on different fibrous structures, and may have widespread biomedical applications.

\section{Hydrophilicity}

Among hydrophilic polymers, PEG-based polymers are probably the most investigated for biomedical applications, as PEG is both non-immunogenic and anti-thrombogenic, as well as being largely resistant to protein adsorption. The anti-biofouling action of PEG-based polymers is the result of both steric and hydration effects and is dependent on the size, branching, and surface-packing density of the specific PEG molecule (Francolini et al., 2015). A high degree of hydration on the surfaces of the polymers is necessary for effective anti-biofouling actions, although the molecular mechanisms and details involved are not fully understood. Jie Zheng and coauthors conducted a computational investigation of the properties of four poly(N-hydroxyalkyl acrylamide) (PAMs) brushes with different carbon spacer lengths (CSLs $=1,2,3$, and 5) using molecular mechanics (MM), Monte Carlo (MC), and molecular dynamics (MD) simulations (Liu et al., 2020a). MM assessed the type of packing structure of the brushes, while MC simulations were used to evaluate the interaction between the brushes and a lysozyme, and MD was utilized for examining the interactions between the brushes, proteins, and water molecules. The results showed that minor variations in the CSL structure are able to influence both the surface hydration and antifouling properties of 


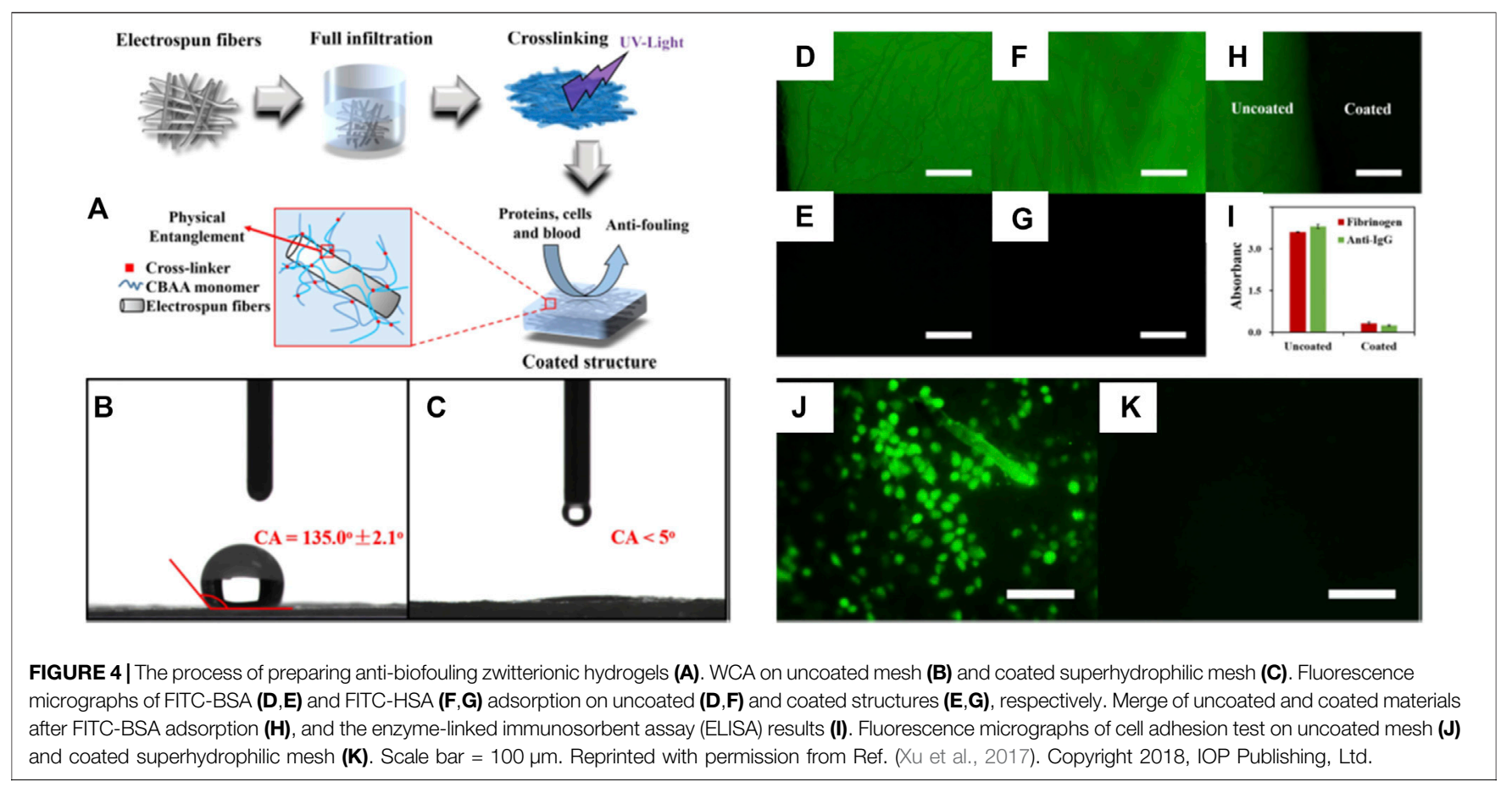

the surface, confirming experimental findings using surface plasmon resonance and sum frequency generation vibrational spectroscopy, as well as measurements of contact angles. These results promote improved understanding of PAM brushes and their properties in relation to anti-biofouling materials and surfaces (Liu et al., 2020a).

Polyurethane (PU) is a commonly used biocompatible polymer, being used in numerous biomedical engineering applications, including dressings, joints, and catheters. Adsorption of proteins to its surface frequently occurs in biological and medical situations, with consequent deleterious effects. Thus, investigation of PUprotein interactions is critical. Both the chemical constituents of the material and its physical topography influence adsorption, and these factors have been extensively investigated over the past few decades. These studies have demonstrated the efficacy of tethering hydrophilic polymers, such as PEO, to the surface. Surfaces modified in this way are strongly resistant to nonspecific protein adsorption, with both the lengths and densities of the PEO chains playing significant roles (Zheng et al., 2010).

In their investigation of suitable materials for preventing the complications of infection and thrombosis in devices making contact with the blood, Francolini and coauthors designed and synthesized a heparin-mimetic segmented PU (Francolini et al., 2012). This introduced sulfate and sulfamate moieties that are responsible for the anticoagulant activity of heparin onto PU. It was found that the modified PU was more hydrophilic than the parent compound. These polymers also reduced the degree of bacterial attachment, measured as colony-forming units (CFUs) found per $\mathrm{cm}^{2}$ of polymer (Figure 5A). These observations were confirmed by SEM (Figures 5B,C), which demonstrated bacterial colonization and aggregation on surfaces lacking the $-\mathrm{SO}_{3} \mathrm{H}$ groups (Figure 5B), and no accumulation of bacteria on surfaces with the $-\mathrm{SO}_{3} \mathrm{H}$ groups (Figure 5C). These results show that increasing the hydrophilicity of the polymer as well as the addition of $-\mathrm{SO}_{3} \mathrm{H}$ groups affected the antifouling action of the surface (Francolini et al., 2012).

\section{Hydrophobicity}

Hydrophilic anti-biofouling polymers tend to swell, resulting in lower space for interaction and thus reduced attachments (Rosenhahn et al., 2010; Eshet et al., 2011). The use of hydrophobic polymers can evade this issue. Hybrid poly(siloxane-urethane) copolymers were developed by Lourdes Irusta and coauthors using isophorone diisocyanate trimers, polycaprolactone triols, and hydroxyterminated PDMS (Santiago et al., 2016). The authors then used quartz crystal microbalance with dissipation monitoring to measure BSA adsorption, observing that the protein was adsorbed in a conformation that did not allow water retention. This indicates that the increased surface hydrophobicity produced by the PDMS was responsible for the improved antifouling action of these copolymers (Santiago et al., 2016). Xinping Wang et al. described the preparation of acrylate block polymer brushes with two 2perfluorooctylethyl methacrylate units at the brush end on an $\mathrm{Au}$ substrate with a "grafting to" method (Wang et al., 2015). It was found that the amount of fibrinogen adsorbed to the surface was reduced in proportion to the hydrophobicity of the perfluoroalkyl chains (Wang et al., 2015).

Suhas S. Joshi and coauthors investigated the effects of introducing femtosecond laser-induced submicron physical structures onto PDMS and PU surfaces for biomedical applications, as shown in Figure 6 (Siddiquie et al., 2020b). Highly regular and single scale submicron laser-induced periodic surface structures (LIPSS), and multiscale structures (MS) containing both submicron- and micronscale features were obtained by femtosecond laser processing on 

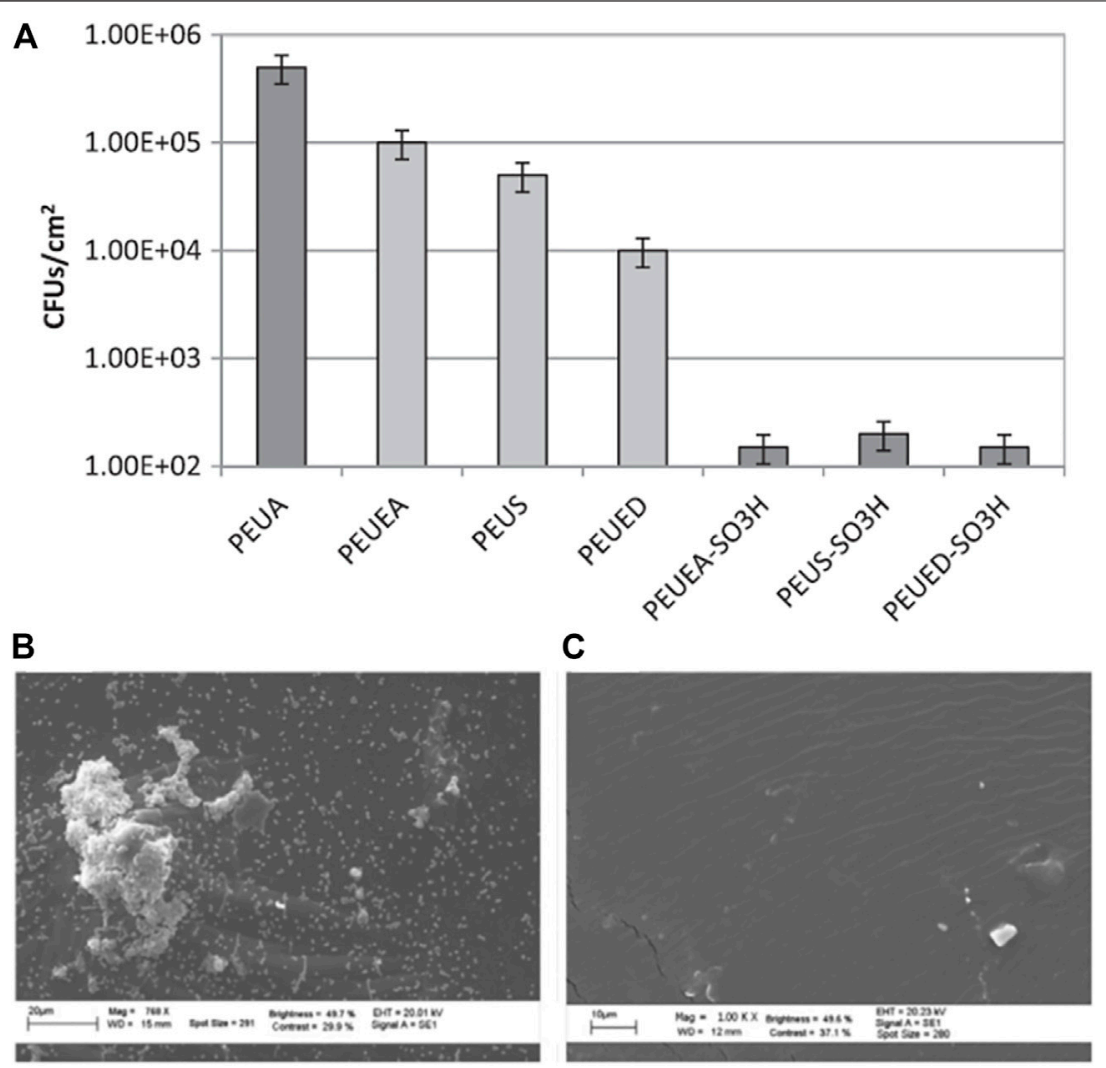

FIGURE 5 | S. epidermidis colony-forming units per $\mathrm{cm}^{2}$ of PEUA (control), amidated, and $-\mathrm{SO}_{3} \mathrm{H}$ group-containing polymers (A). SEM results showing the aggregates of bacterial on the PEUA surface (B) and the absence of aggregates on the PEUEA-SO ${ }_{3} \mathrm{H}$ surface (C) after 24 h of exposure. Reprinted with permission from Ref. (Francolini et al., 2012). Copyright 2012, Elsevier B.V.

stainless-steel (SS) substrates and following replicate processing with PDMS and PU elastomers. Surface hydrophobicity was enhanced on LIPSS and MSs surfaces (Figure 6A). It was observed that the hydrophobic submicron-textured PDMS and PU surfaces were stable and performed well for up to $100 \mathrm{~h}$ when immersed (Figure 6B). E. coli attachment was significantly reduced (>89\%) on both LIPSS- and MS-modified surfaces (Figures 6C,D).

\section{ANTI-BIOFOULING POLYMERS WITH SPECIAL SURFACE WETTABILITY FOR BIOMEDICAL APPLICATIONS}

As discussed in Section 2 above, various strategies to achieve different surface wettability can produce anti-biofouling ability for different biomedical applications with extensive alternative schemes. In this section, we will review the applications of antibiofouling polymers with special surface wettability in typical biomedical fields both in vivo and in vitro, including cardiology, ophthalmology, and nephrology.

\section{Heart Valves in Cardiology}

Although the bioprosthetic heart valve (BHV) has been used in clinical applications, there are still some complications, including calcification and thrombosis, which will shorten the service life of BHV. Hydrophilic polymers such as PAA are usually utilized to enhance the anti-biofouling actions of materials (Zhang et al., 2021c). Our previous article proposed a strategy to fabricate a hydrophilic-coated antibiofouling BHV using PAA and PDMS in the inner and outer valves (Lei et al., 2021). We evaluated the anti-biofouling properties, including anti-coagulation, anti-cell adhesion, anti-calcification, and ability to resist BSA adsorption, both in vivo and in vitro (Figure 7 ). The anti-biofouling-coated sample (PHIL) was significantly better than the GLUT-treated control sample in various tests, including attachment of L929 cells, whole blood, FITC-BSA, and calcification. These results indicate the effectiveness of this method to produce hemocompatible biomedical materials with good antibiofouling abilities.

Polymeric heart valves have attracted much attention (Bezuidenhout et al., 2015; Guo et al., 2019; Kambe et al., 2019). Xing Zhang and coauthors reported that a composition of PEGDA hydrogels and polyethylene terephthalate/polyamide6 (PET-PA6) fabric (PEGDA/PET-PA6) was fabricated to form artificial heart valve leaflets (Guo et al., 2019). The WCA on the PET-PA6 fabric was about $129^{\circ}$ (Figure 8A) but it decreased to about $41^{\circ}$ (Figures 8B,C) after the introduction of PEGDA 

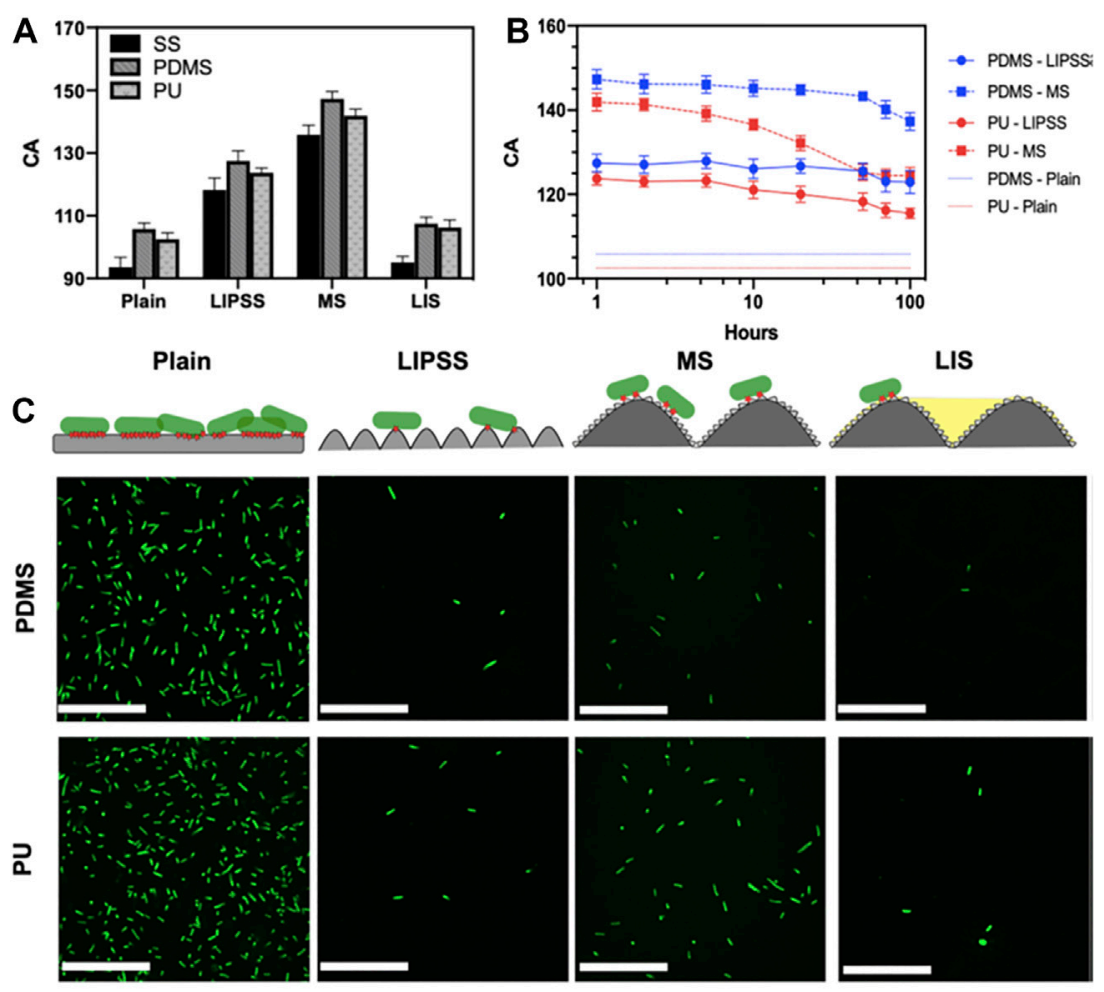

D

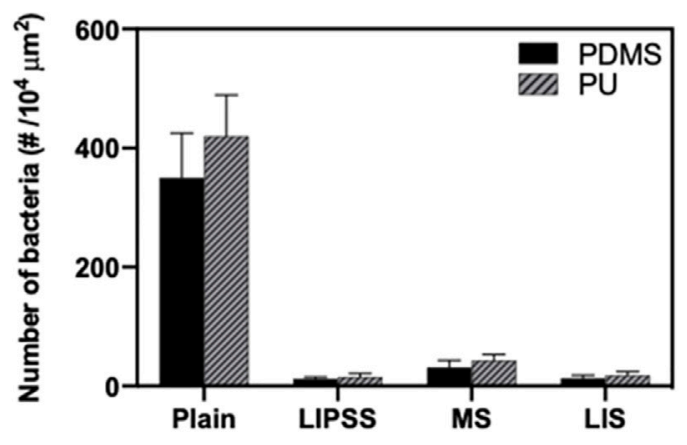

FIGURE 6 | Static WCA on unmodified, LIPSS-, and MSs-modified SS, PDMS, and PU surfaces (A). Differences in water CA with different immersion times (B). Bacteria on the different surfaces (C, above). Bacterial contacts on the surfaces are shown in red, and fluorescence micrographs indicate bacterial attachment to different PDMS and PU surfaces (below). Numbers of attached bacteria in relation to topography (D). Reprinted with permission from Ref. (Siddiquie et al., 2020b). Copyright 2020, American Chemical Society.

hydrogels, showing an obvious increase of surface hydrophilicity. After porcine platelet-rich plasma was cultivated for $2 \mathrm{~h}$, a few platelets were seen on the PET-PA6 material (Figures 8D,E), while none were visible on the PEGDA/PET-PA6 composite (Figures 8F,G). Therefore, the increased hydrophilicity from the PEGDA hydrogels could enhance the anti-biofouling ability of the composite artificial heart valve leaflets with a low thrombogenic risk when interacting with blood.

\section{IOLs and CLs in Ophthalmology}

Biofoulant adhesion, including the attachment of bacteria, cells, or proteins, to devices such as IOLs can result in the failure of the implant. We fabricated a simple and economical PVA coating with or without the introduction of a "bridge." The "bridge" comprised an intermediate adhesive layer (AL) to augment the interaction between the coating and the IOL material (Figure 9A) (Lan et al., 2021). Cell proliferation on the material was measured using CCK- 8 assays (Figure 9B) and the adhesion of L929 cells measured by CLSM is shown in Figure 9C. The fluorescent protein adsorption performance and the fluorescence intensity of FITC-BSA on different samples were shown in Figure 9D. Increasing the PVA coating time to $10 \mathrm{~s}$ resulted in a reduction in the WCA to approximately $63^{\circ}$, in conjunction with augmented hydrophilicity and anti-biofouling action against both L929 

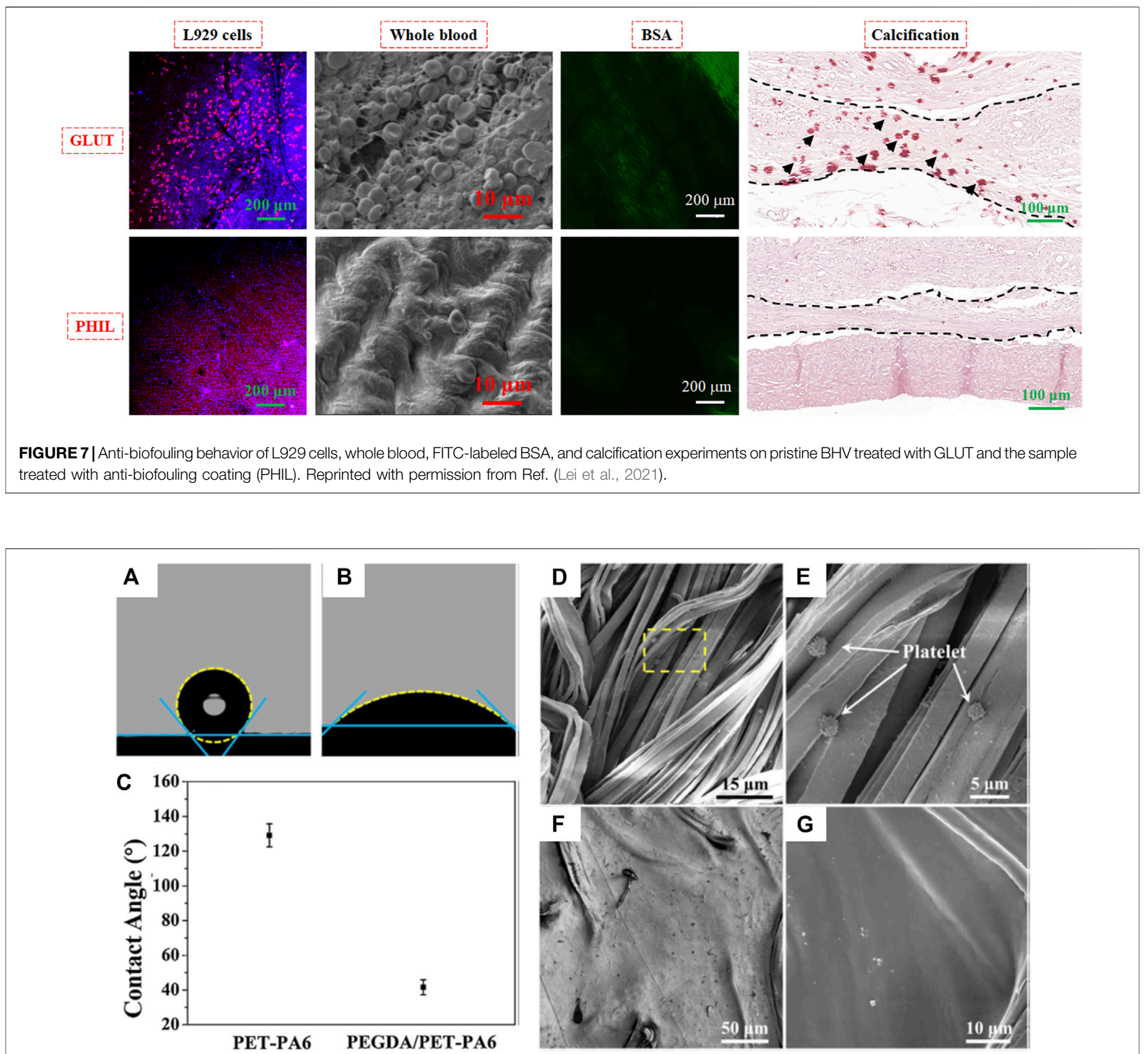

FIGURE 8 | Profiles of water droplets on PET-PA6 fabric (A) and PEGDAPET-PA6 composite (B), and WCA results of the samples (C). SEM micrographs showing platelet adherence on the PET-PA6 fabric (D,E) and PEGDA/PET-PA6 composites (F,G). Reprinted with permission from Ref. (Guo et al., 2019). Copyright 2019, Elsevier B.V.

cells and BSA. The coating prepared by AL "bridge" could greatly improve the mechanical stability of PVA coating on PMMA IOL surface to extend the lifetime of anti-biofouling ability, which could provide a new means of preparing a transparent hydrophilic anti-biofouling PVA coating applicable to IOLs.

Besides the IOL, CLs are a common application in ophthalmology and the development of anti-biofouling CLs would ensure safety. Gongyan Liu and coauthors introduced the zwitterionic anti-biofouling carboxybetaine groups onto the surface of CLs to significantly increase their wettability and reduce their adsorption of bacteria and proteins (Liu et al., 2020c). Yiyan Yang and coauthors reported a series of polymers that were conjugated with adhesive catechol, antibiofouling PEG, and hydrophobic urea/ethyl onto branched poly(ethylenimine). The CLs were coated by immersing in aqueous solutions of the modified polymers, and the coating was found to tolerate autoclaving, remaining on the device for its lifetime of approximately 7 days (Cheng et al., 2015). Silicone is widely utilized in biomedical devices, and the most commonly used silicone is PDMS as it is transparent, inert, inflammable, and non-toxic. Chun-Jen Huang and 

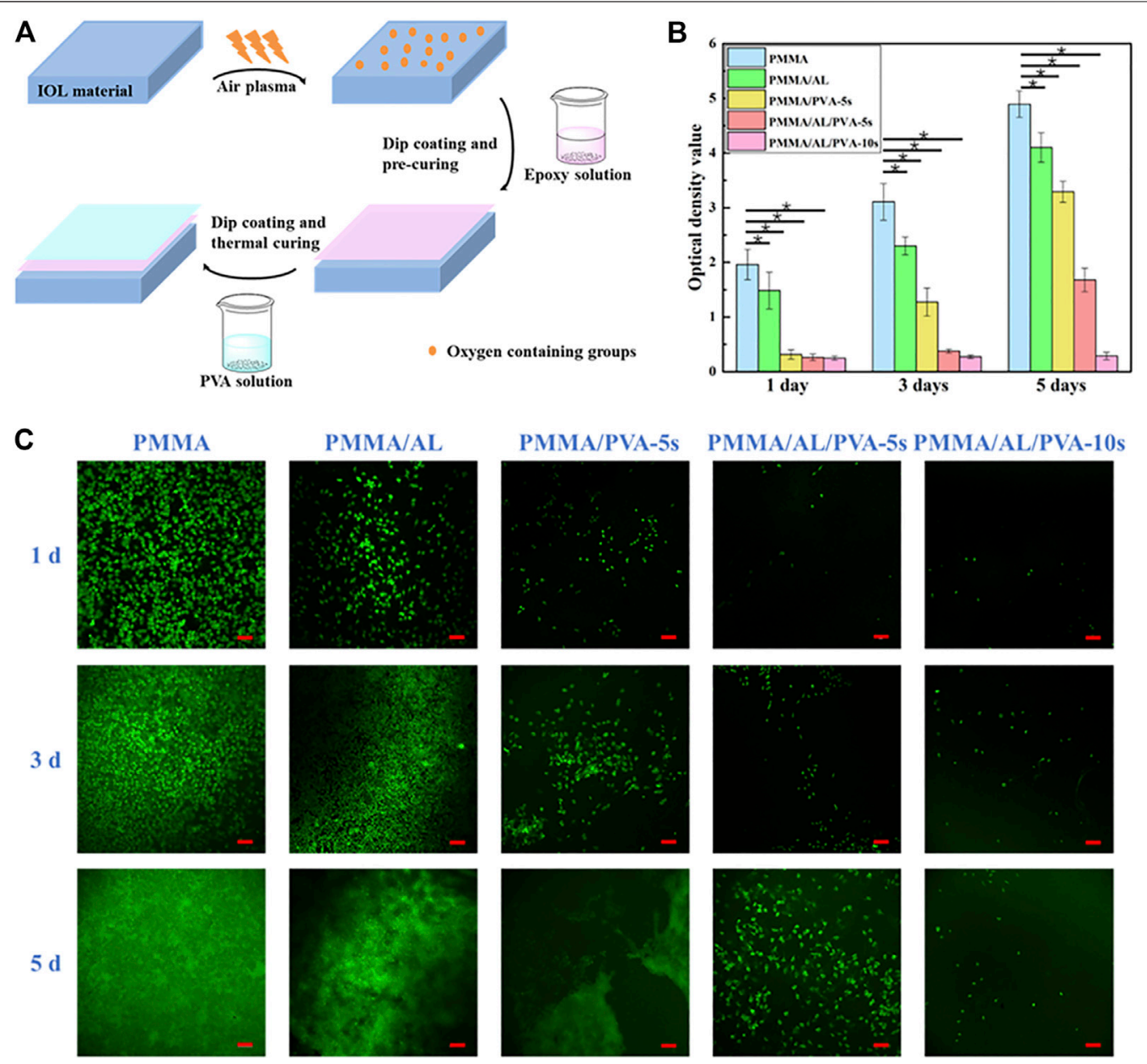

D

PMMA
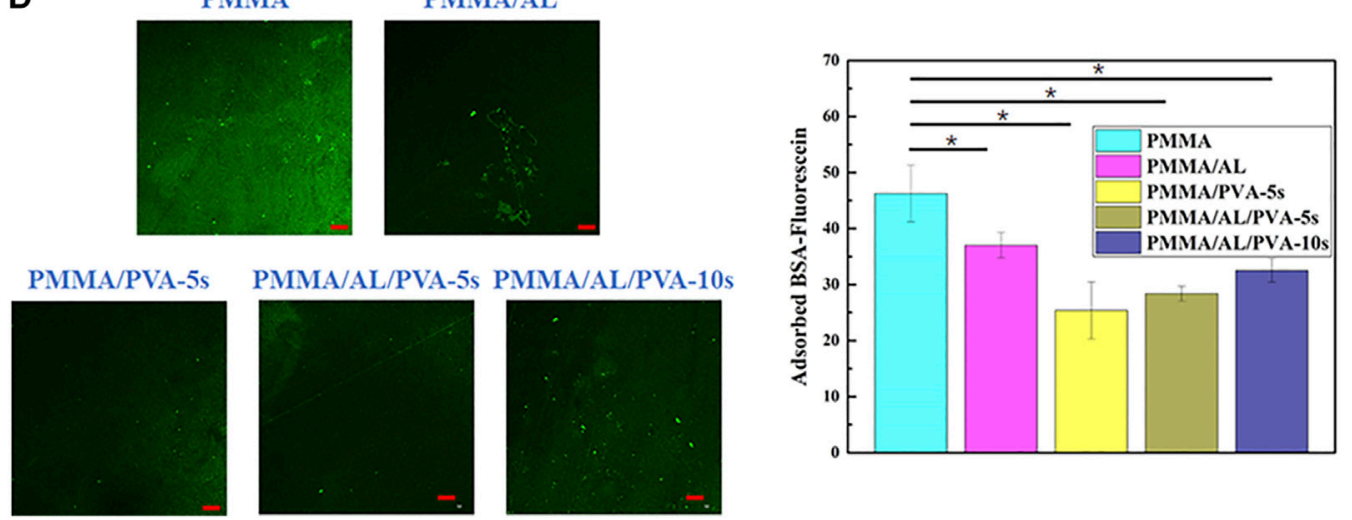

FIGURE 9 | Fabrication process of hydrophilic PVA with an intermediate AL on PMMA IOL surface (A). Cell proliferation measured by CCK-8 assay (B) and proliferation at 1, 3, and 5 days pre- and post-modification (C). Fluorescent protein absorbance (D, left) and the fluorescence intensity (D, right) of FITC-BSA in different samples. Reprinted with permission from Ref. (Lan et al., 2021). Copyright 2021, Royal Society of Chemistry.

coauthors developed a stable superhydrophilic zwitterionic interface on PDMS by covalent silanization of sulfobetaine silane (SBSi) (Yeh et al., 2014). This was effective against biofouling by both Pseudomonas aeruginosa and $S$. epidermidis even after storage for 30 days at room temperature (Figures 10A-C), and the SBSi-modified commercially available silicone hydrogel CLs showed similar excellent anti-biofouling ability. Meanwhile, the adsorption of BSA, mucin, lysozyme (Figures 10D-F) and sulforhodamine B sodium (SRB)-encapsulated liposomes (Figures 10G,H) on SBSi-tailored PDMS showed an obvious decrease compared with that on pure PDMS. 

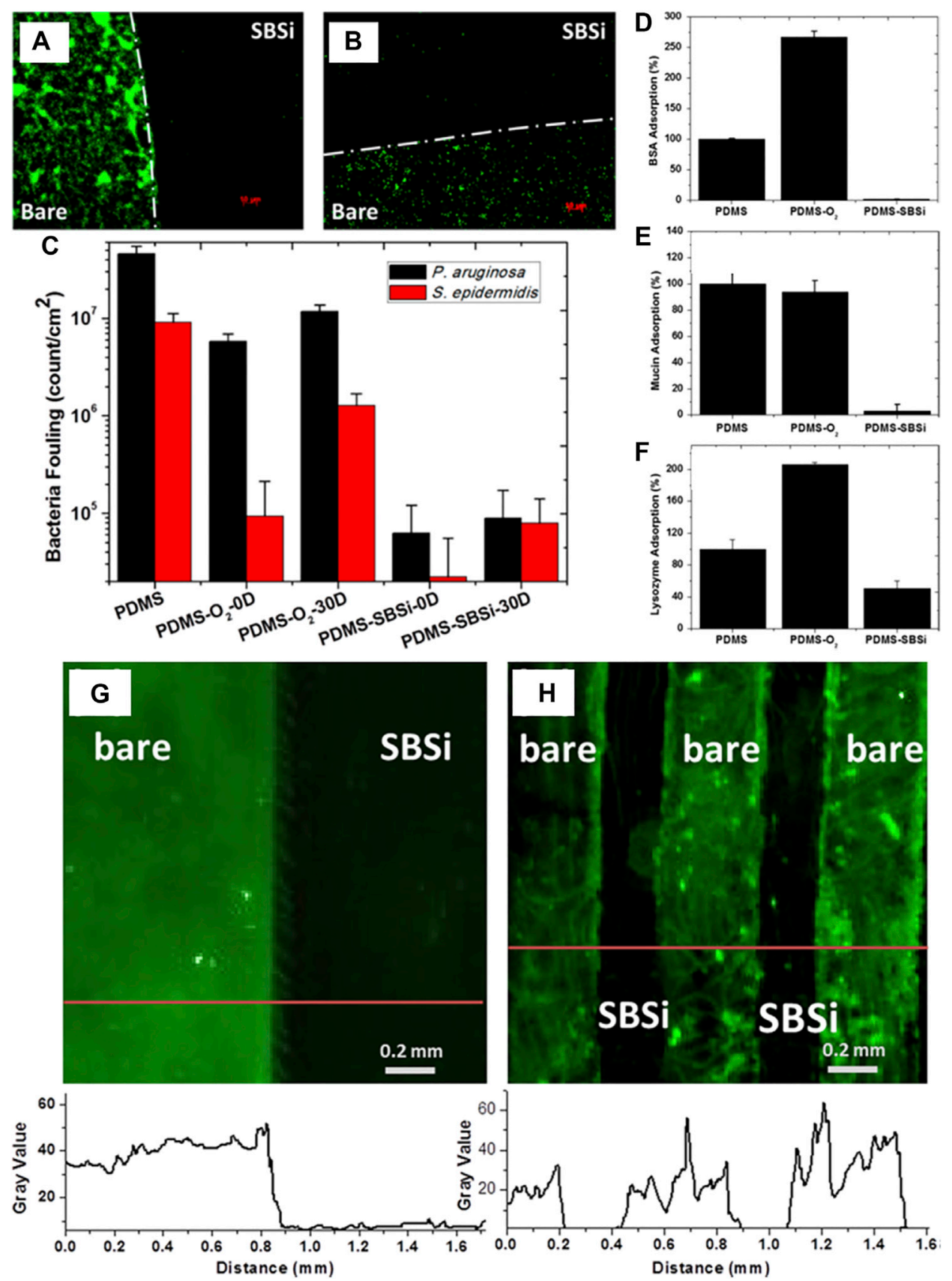

FIGURE 10| Fluorescence micrographs showing P. aeruginosa (A) and S. epidermidis (B) adsorption to partially modified PDMS. Quantification of adsorption on PDMS samples as a function of treatment and time (C). Enzyme-linked immunosorbent assay (ELISA) measurements for adsorption of BSA (D), mucin (E), and lysozyme (F) on samples of PDMS, PDMS-O ${ }_{2}$, and PDMS-SBSi. Adsorption of SRB-encapsulated liposomes on SBSi-patterned PDMS samples prepared by elastomeric stencil (G) and microchannels (H). Fluorescence intensities are indicated by red lines below the images. Reprinted with permission from Ref. (Yeh et al., 2014). Copyright 2014, American Chemical Society.

\section{Urinary Catheters and Hemodialysis Membranes in Nephrology}

Urinary catheters and hemodialysis membranes are the typical polymer materials used in nephrology. Various strategies to prevent bacterial adhesion and growth on medical devices have been developed. Poloxamers are nontoxic hydrophilic copolymers and Poloxamer 338 (P388) can be used to prevent the formation of biofilm and consequent infection. The antibiofouling behavior was investigated by the adhesion of Ec5FSL and Ec9FSL E. coli on a segment of a hydrophilic P388-adsorbed silicone urinary catheter compared to an uncoated segment. Neither E. coli isolate was detected on the former due to the 
A Step 1.

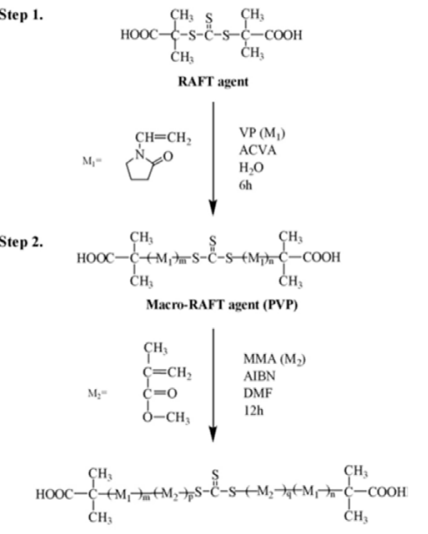

B

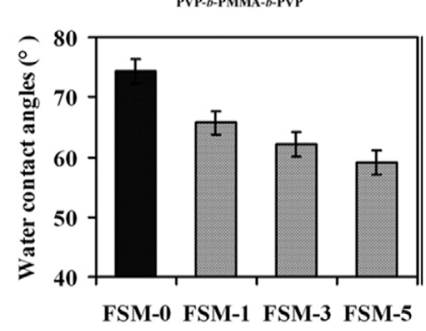

C
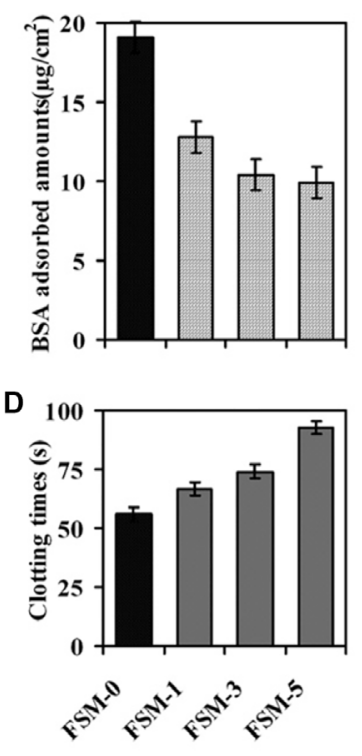

E
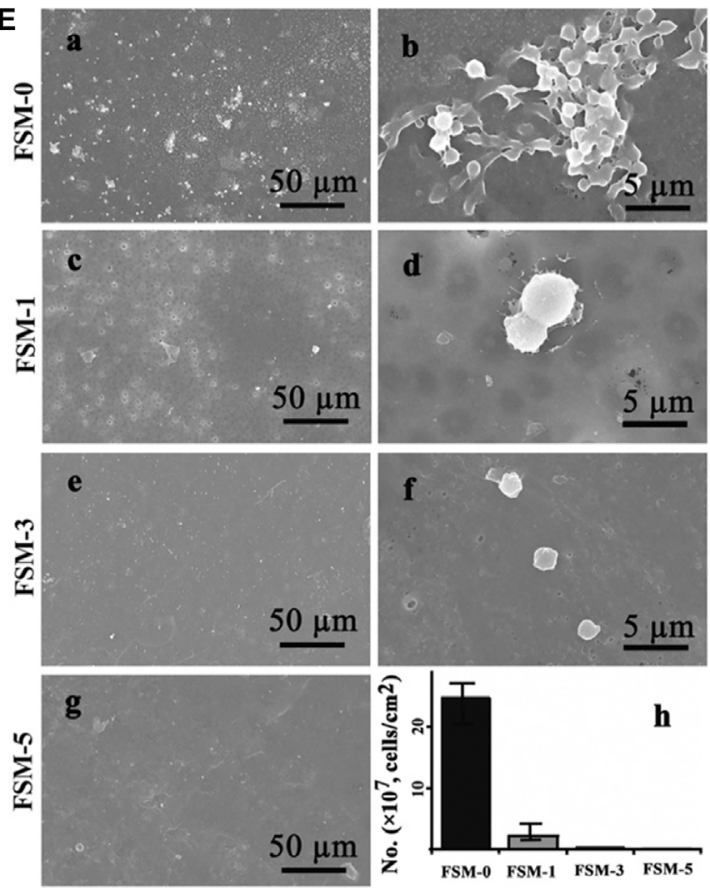

FIGURE 11 | Synthesis of the PVP-b-PMMA-b-PVP block copolymer (A). WCA of the modified membranes (B). BSA adsorption (C). Activated partial thromboplastin time (D). SEM micrographs showing platelet adhesion (E, h, number of the adherent platelets on the membranes adsorbed from platelet-rich plasma estimated from the SEM pictures). Reprinted with permission from Ref. (Ran et al., 2011). Copyright 2011, Elsevier B.V.

excellent anti-biofouling ability of hydrophilic P388 (Stirpe et al., 2020).

Hemodialysis membrane is another typical example of a nephrological application. PSF is frequently used for ultrafiltration membranes due to its stability under various conditions (Xie et al., 2015; Yin et al., 2015). A variety of surface modifications for ultrafiltration membranes have been investigated to combat biofouling. A novel zwitterionic molecule, MPDSAH, was grafted onto PSF membranes using benzophenone to increase their anti-biofouling actions (Yu et al., 2009). Measurement of WCA indicated the enhancement of membrane hydrophilicity by this modification. The passage of water was somewhat reduced by the modification, while adsorption of BSA was significantly reduced. The increase in anti-biofouling action was shown to be related to increased surface hydrophilicity (Yu et al., 2009). The immobilization of heparin on PSF allowed use of the membrane for dialysis. The higher the heparin density, the lower WCA and the platelet adherence. The flux of the heparin-modified membrane also recovered well after BSA filtration, indicating the improved anti-biofouling action of the heparin-modified membrane (Huang et al., 2011).

PES is a typical PSF and is frequently used for hemodialysis membranes. Poly (citric acid)-grafted-MWCNT (PCA-gMWCNT) was included as a nanofiller in PES to generate a hemodialysis mixed-matrix membrane (MMM) with improved hydrophilicity (from $77^{\circ}$ to $56^{\circ}$ ) and antibiofouling ability (Abidin et al., 2016). The passage of pure water and the resistance to BSA were increased as a result of the presence of numerous hydrophilic groups derived from PCA-g-MWCNT (Abidin et al., 2016). Changsheng Zhao and coauthors synthesized a hydrophilic triblock copolymer of PVP- $b$-PMMA- $b$-PVP via reversible addition-fragmentation chain transfer polymerization (Figure 11A) (Ran et al., 2011). After the introduction of the copolymer, the membranes showed a lower WCA (Figure 11B), lower BSA adsorption (Figure 11C), prolonged blood coagulation times (Figure 11D), and reduced platelet adhesion (Figure 11E). These results suggested that modifying the surface hydrophilicity of PES improves their anti-biofouling action, allowing the membranes to be used for blood purification, including hemodialysis (Ran et al., 2011).

PHEMA, the simplest hydroxylated polymethacrylate, can impart an anti-biofouling character to surfaces. Lixin Xue and coauthors reported another hemodialysis membrane based on biobased and biodegradable PLA and PHEMA (Zhu et al., 2015). Anti-biofouling and hemocompatible PLA membranes were developed using different concentrations of PLA-PHEMA copolymers as the blending additive (M0 indicates pure PLA membrane, and M20 indicates $20 \mathrm{wt} \%$ copolymer). The results showed that PLA/PLA-PHEMA membranes with high PLA-PHEMA concentrations showed augmented hydrophilicity (WCA decreased from $75^{\circ}$ for M0 to $60^{\circ}$ for M20), water permeability, anti-biofouling (decreased BSA adsorption and platelet adhesion, Figures 2, 12A,C,D) and 

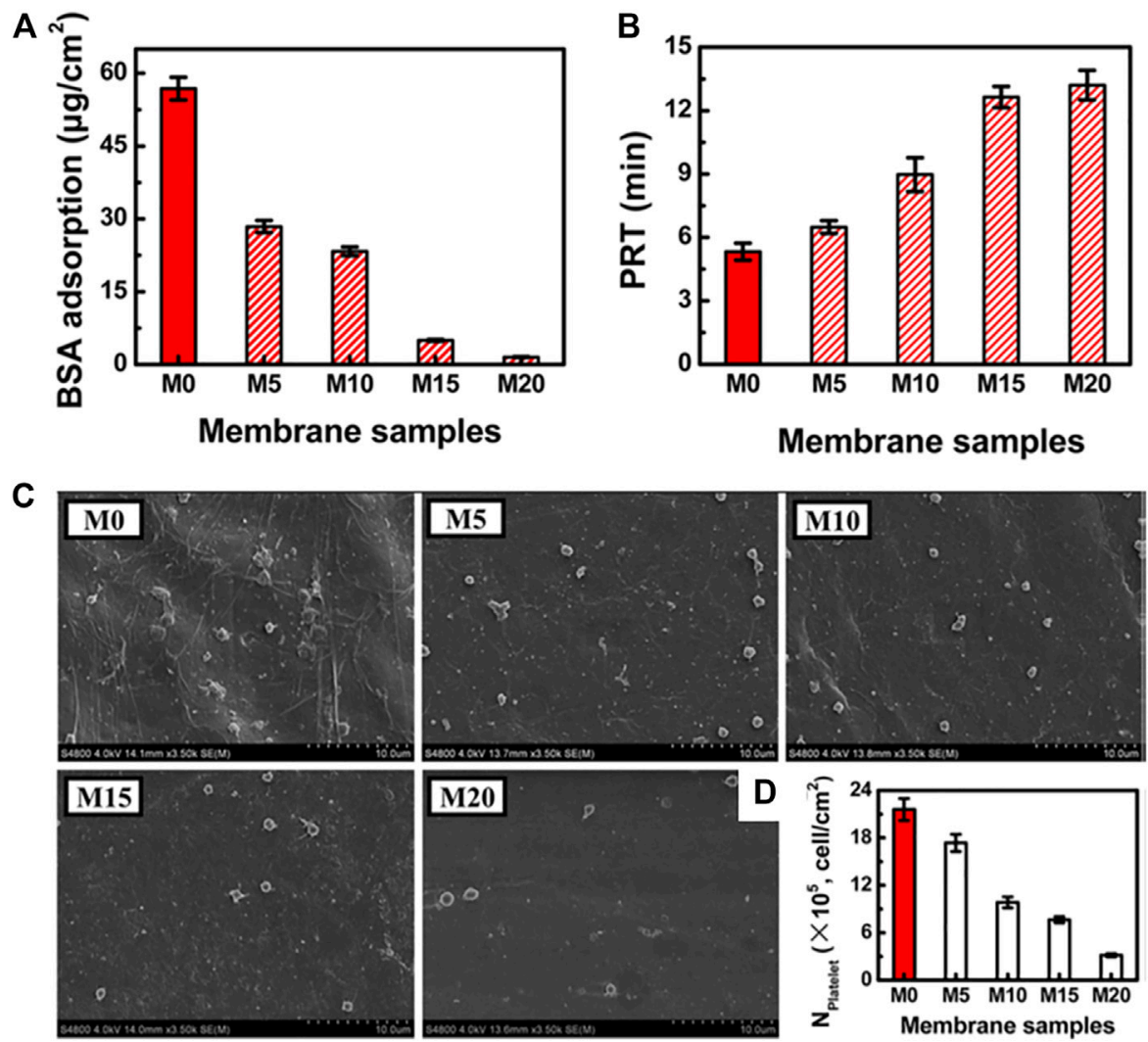

FIGURE 12 | Hemocompatibility of M0 and PLA/PLA-PHEMA membranes (M5, M10, M15, and M20). Adsorption of BSA to membranes (A). Plasma recalcification times for membranes (B). SEM micrograph (C) and the number (D) of adherent platelets on the membrane surfaces. Reprinted with permission from Ref. (Zhu et al., 2015). Copyright 2015, American Chemical Society.

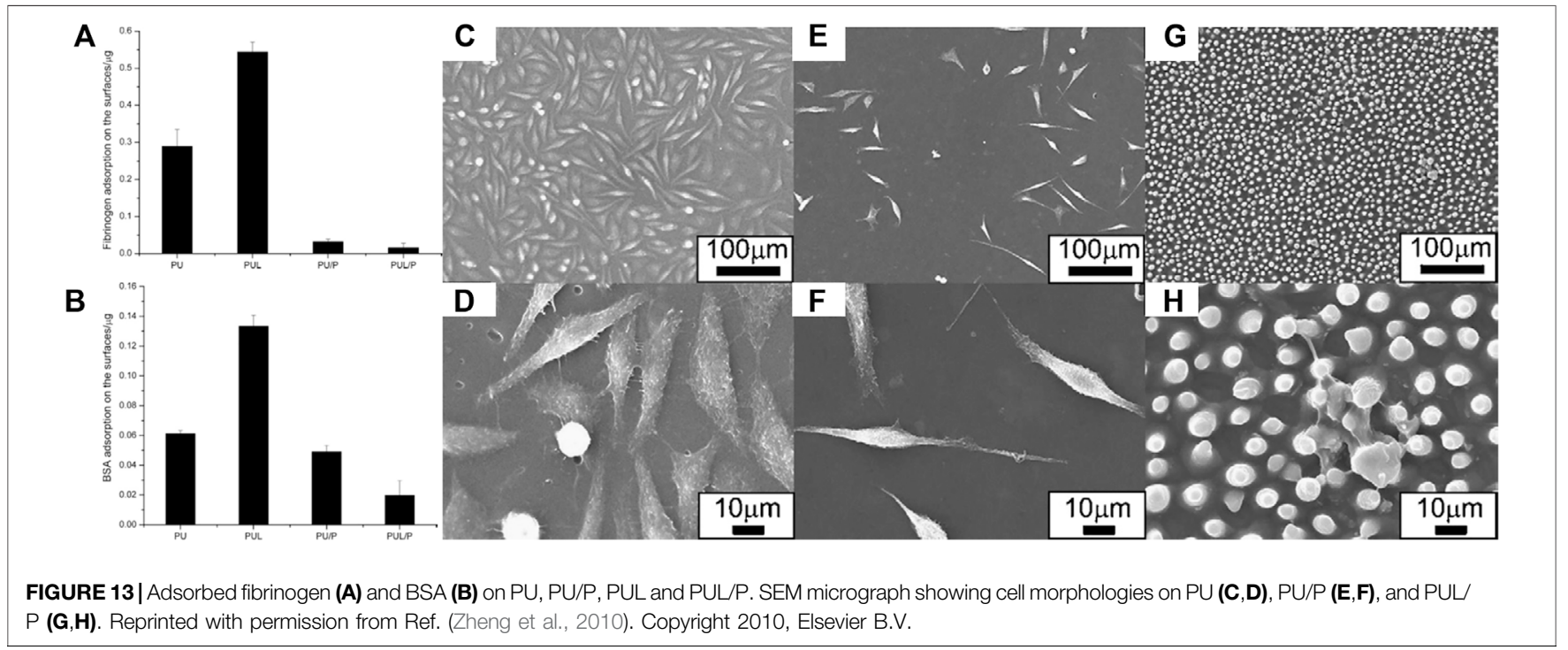

hemocompatibility (increased plasma recalcification time (PRT), Figure 12B). These findings indicate that PLAPHEMA copolymers were effective in optimizing PLA membranes for hemodialysis applications (Zhu et al., 2015).

\section{CONCLUSION AND OUTLOOK}

The ability of polymers to combat biofouling can be enhanced by the regulation of special surface wettability, including 

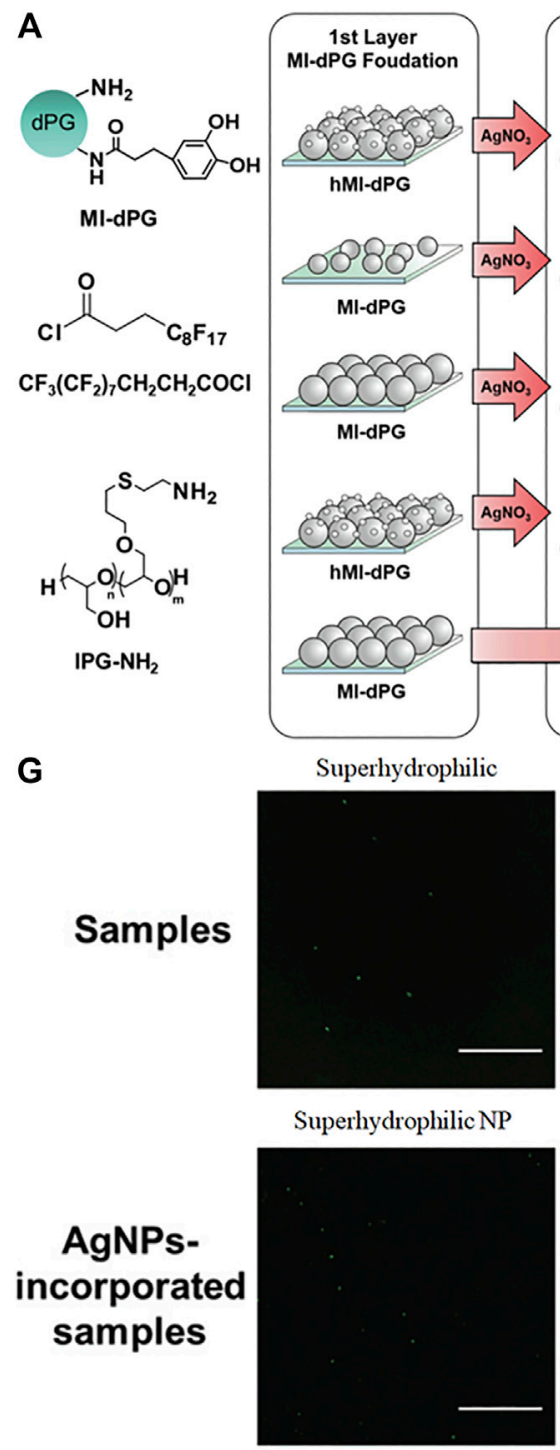

MIdPG

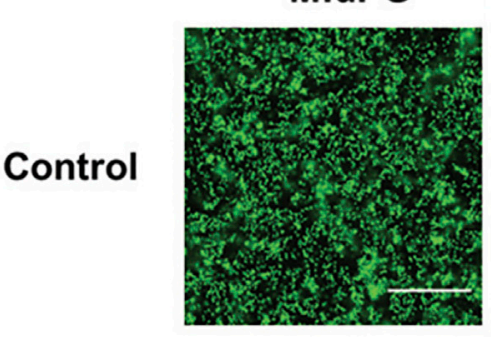

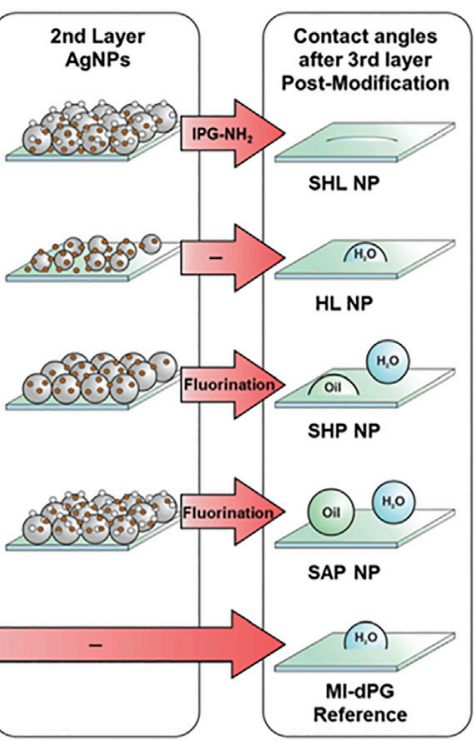
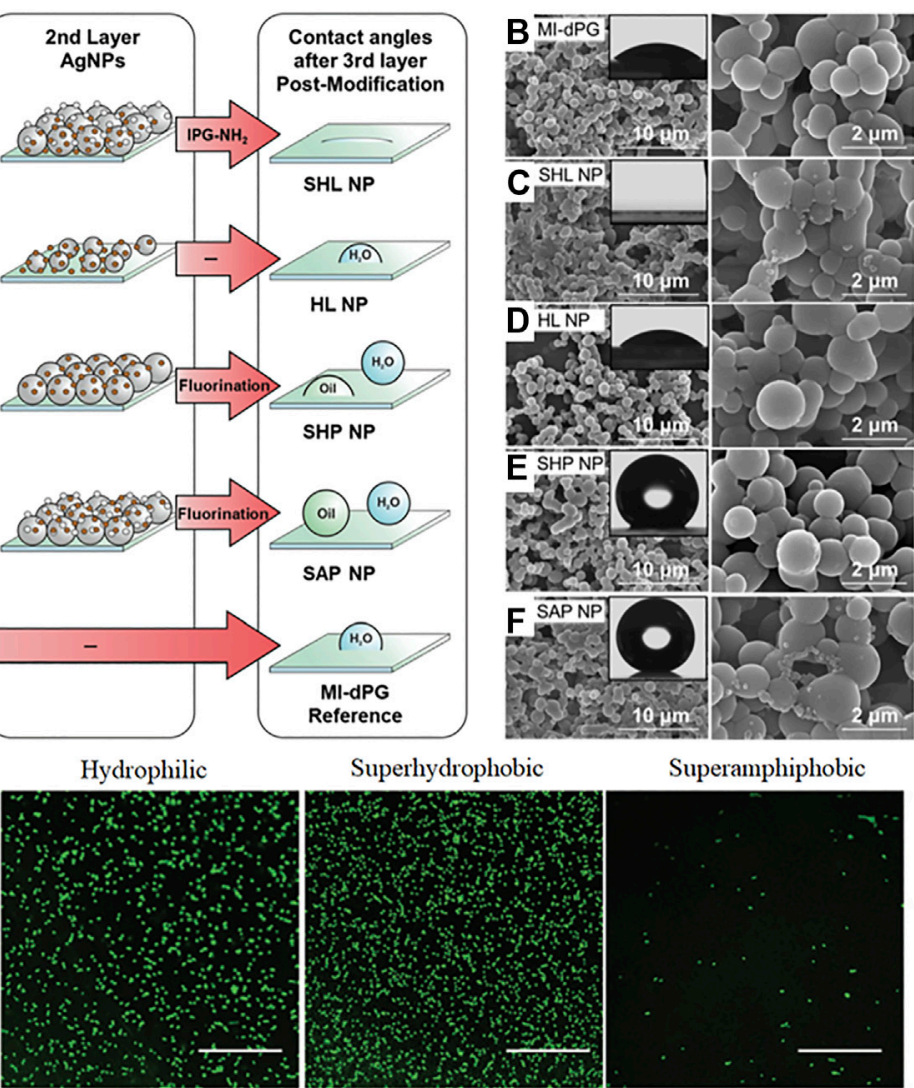

Superhydrophobic

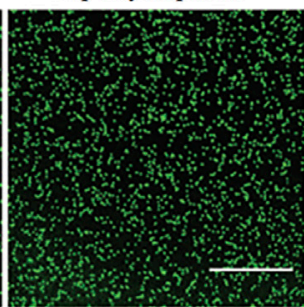

Superhydrophobic NP

Superamphiphobic NP
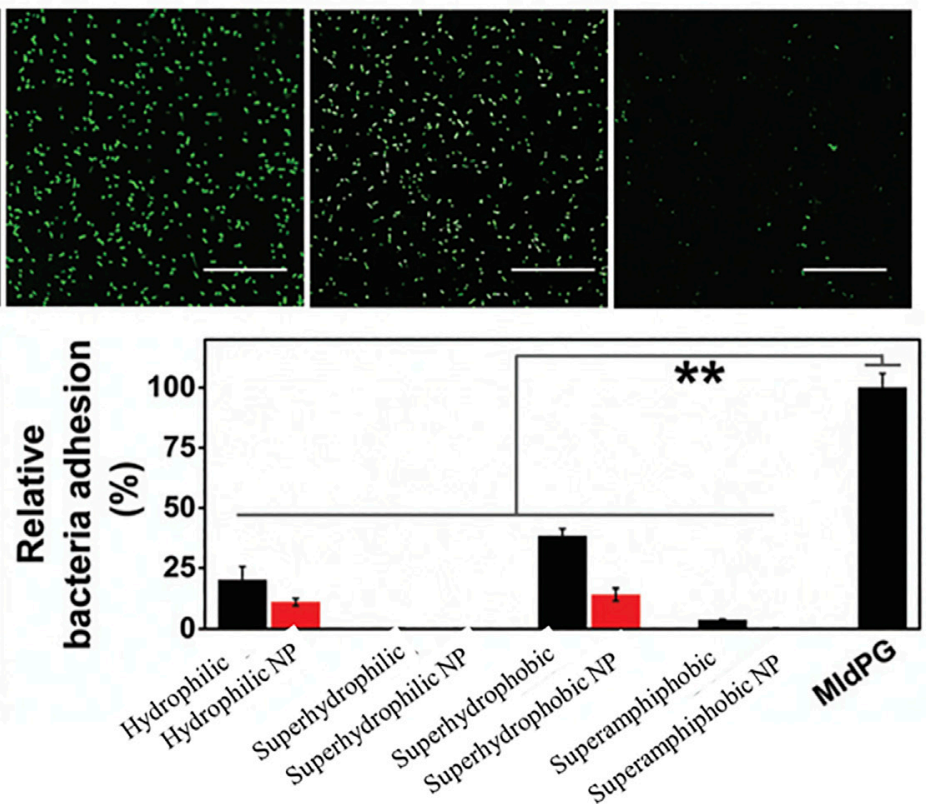

FIGURE 14 | Fabrication process (A) of Ml-dPG based coatings with different wettability characteristics and physical structures, MI-dPG (B), superhydrophilic NP

(C), hydrophilic NP (D), superhydrophobic NP (E), superamphiphobic NP (F). Quantification of bacterial attachment and their corresponding micrographs (G). Reprinted with permission from Ref. (Li et al., 2019b). Copyright 2019, Royal Society of Chemistry. 
superhydrophilicity, hydrophilicity, hydrophobicity, and superhydrophobicity. In this review, we focus on the antibiofouling polymers with superhydrophilicity, hydrophilicity and hydrophobicity but excluding superhydrophobicity which can be found in our previous review (He et al., 2021). Meanwhile, we just focus on the biomedical applications in cardiology, ophthalmology, and nephrology. Moreover, biofoulants mentioned in this review are focused on the usual bacteria, cells, and proteins. This review will provide a new perspective to promote the development of anti-biofouling polymers. Meanwhile, the anti-biofouling strategies reviewed in this manuscript will offer help for future researchers to choose suitable polymers for specific anti-biofouling applications. Considering the biomedical applications of anti-biofouling polymers, most research has focused on materials with superhydrophilicity or hydrophilicity which may be more achievable than hydrophobicity or superhydrophobicity. However, there is still some research that obtained excellent anti-biofouling polymers by hydrophobic manipulation. Therefore, exploring more anti-biofouling polymers with hydrophobic or superhydrophobic properties should be a research priority in the future to avoid the drawbacks of antibiofouling polymers with hydrophilic properties. Meanwhile, there are some issues that should be paid more attention, that are discussed below.

\section{Exploring the Inherent Correlation Between the Anti-Biofouling and Surface Wettability}

Protein adsorption depends not only on the hydrophilic or hydrophobic properties of materials, but also on topographical features, including surface curvature, roughness, and geometrical characteristics. There is research focusing on the effects of surface micro- or nano-typography on adsorption. In 1964, Curtis and Varde described the effects of surrounding topography on cells. It is generally accepted that both the topography and chemical characteristics of surfaces can influence the growth and properties of cells (Zheng et al., 2010). Hong Chen and coauthors fabricated lotus leaf-like polyurethane/Pluronic ${ }^{\circledR}$ F-127 surface (PUL/P) by replica molding using a lotus leaf as the template (Zheng et al., 2010). When water droplets touched the superhydrophilic PUL/P surface, the drop spread rapidly with a WCA near zero, suggesting enhancement of the surface by the adoption of the lotus leaf-like structure compared to those without (PU/P). Adsorption of both BSA and fibrinogen was significantly lower on the PU/P surface (Figures 13A,B). Further reductions in adsorption were observed on the superhydrophilic PUL/P surface (Figures 13A,B). Experiments with $\mathrm{L} 929$ cells showed that cells adhered less to PU/P surfaces (Figures 13C-F). Meanwhile, cell adhesion to the superhydrophilic $\mathrm{PUL} / \mathrm{P}$ was reduced with cells showing spherical shapes and diminished viability (Figures 13G,H). The superhydrophilic PUL/ $\mathrm{P}$ thus appears to resist non-specific protein adsorption and cell attachment, with these effects deriving from both topographical and chemical structures. However, adsorption and adhesion to the hydrophobic lotus leaf-like polyurethane surface (PUL) were obviously enhanced compared with the hydrophilic PU, in apparent contradiction of the anti-biofouling strategies based on hydrophobic polymers discussed in section 2.3. Biofoulants adsorption and adhesion may be increased or decreased with the increased hydrophobicity. Therefore, the inherent correlation between the anti-biofouling and surface wettability was still nonuniform, and in-depth research should be applied. A comprehensive consideration and more quantitative research of the influence of chemical compositions and physical structures on the anti-biofouling ability should be under consideration.

\section{Design and Fabrication of Surfaces}

Both chemical and physical properties influence the resistance of surfaces to biofoulants. This is borne out in natural antifouling materials (Magin et al., 2010). Rainer Haag and coauthors reported the effect of extreme wettability ranging from superhydrophilicity to superhydrophobicity on the antibacterial efficiency of an MI-dPG and silver nanoparticle (AgNPs) coating (Li et al., 2019b). As shown in Figure 14A, MI-dPG or hierarchical micro- and nanometer roughed MI-dPG (hMI-dPG) was formed by controlling surface polymerization and subsequent modification by AgNPs, linear polyglycerol (lPG- $\left.\mathrm{NH}_{2}\right)$ or fluorination. Different surface wetting properties containing superhydrophilic, hydrophilic, superhydrophobic, and even superamphiphobic wettability were achieved by different post-functionalization without obvious physical structural changes, demonstrated by WCA and SEM (Figures 14B-F). The resulting superhydrophilic polymer coatings were effective in repelling both E. coli and S. aureus, and the coating properties in relation to their antibacterial activities are shown in Figure 14G. The results indicated that the polymer coatings with superhydrophilic or superamphiphobic properties had good anti-biofouling ability but those with hydrophilic and superhydrophobic character showed less anti-biofouling ability.

Therefore, it is necessary to develop surfaces with quantifiable physical structures for optimization of anti-biofouling action. We previously reported a simple and mold-free technique for fabricating surfaces by 3D printing ( $\mathrm{He}$ et al., 2017), which may assist in the precise design and manufacture of physical surfaces to combat biofouling (Mazinani et al., 2019).

\section{Anti-biofouling Polymers With Good Biocompatibility}

Biocompatibility is defined as the ability of a material to perform with an appropriate host response in a specific application (Grainger, 1999; Barrère et al., 2008). It is an important issue for the chosen of anti-biofouling polymer types especially when these materials will be used in biomedical fields. If anti-biofouling polymers used in vivo are not biocompatible, they will elicit pernicious local or systemic inflammatory responses and induce the biomedical implants failed. Therefore, good biocompatibility should be paid more attention in the future researches of anti-biofouling polymers with special surface wettability.

\section{Long-Term Anti-Biofouling Polymers}

Anti-biofouling surfaces are easily damaged by scratching, degradation, and rough handling. This damage destroys the surface characteristics leading to a loss of anti-biofouling 
activity. The development of robust and long-lasting anti-biofouling polymers remains a major challenge (Wu et al., 2019). Investigation of self-repairing materials, inspired by the repair mechanisms seen in natural organisms (Cai et al., 2014) would be advantageous to maintain and restore the properties of surfaces. This is a promising strategy for obtaining long-term and robust antibiofouling surfaces (Wang et al., 2011; Chen et al., 2015a; Chen et al., 2015b; Chen et al., 2016; Liu and Guo, 2018; Wang et al., 2020).

\section{AUTHOR CONTRIBUTIONS}

$\mathrm{ZH}, \mathrm{XL}$, and FD conceived and designed this review paper; $\mathrm{ZH}$ and XL wrote this review paper; XY, NW, LM, JP, HL, and FD revised this review paper.

\section{REFERENCES}

Abidin, M. N. Z., Goh, P. S., Ismail, A. F., Othman, M. H. D., Hasbullah, H., Said, N., et al. (2016). Antifouling Polyethersulfone Hemodialysis Membranes Incorporated with Poly (Citric Acid) Polymerized Multi-Walled Carbon Nanotubes. Mater. Sci. Eng. C 68, 540-550. doi:10.1016/j.msec.2016.06.039

Almeida, E., Diamantino, T. C., and de Sousa, O. (2007). Marine Paints: The Particular Case of Antifouling Paints. Prog. Org. Coat. 59 (1), 2-20. doi:10.1016/ j.porgcoat.2007.01.017

Ammons, M. C., and Copié, V. (2013). Mini-review: Lactoferrin: A Bioinspired, Anti-biofilm Therapeutic. Biofouling 29 (4), 443-455. doi:10.1080/ 08927014.2013.773317

Azemar, F., Faÿ, F., Réhel, K., and Linossier, I. (2015). Development of Hybrid Antifouling Paints. Prog. Org. Coat. 87, 10-19. doi:10.1016/j.porgcoat.2015.04.007

Ball, P. (1999). Engineering Shark Skin and Other Solutions. Nature 400 (6744), 507-509. doi:10.1038/22883

Barrère, F., Mahmood, T. A., de Groot, K., and van Blitterswijk, C. A. (2008). Advanced Biomaterials for Skeletal Tissue Regeneration: Instructive and Smart Functions. Mater. Sci. Eng. R: Rep. 59 (1), 38-71. doi:10.1016/j.mser.2007.12.001

Bezuidenhout, D., Williams, D. F., and Zilla, P. (2015). Polymeric Heart Valves for Surgical Implantation, Catheter-Based Technologies and Heart Assist Devices. Biomaterials 36, 6-25. doi:10.1016/j.biomaterials.2014.09.013

Bixler, G. D., and Bhushan, B. (2012). Biofouling: Lessons from Nature. Phil. Trans. R. Soc. A. 370, 2381-2417. doi:10.1098/rsta.2011.0502

Bixler, G. D., and Bhushan, B. (2013). Fluid Drag Reduction and Efficient SelfCleaning with Rice Leaf and Butterfly Wing Bioinspired Surfaces. Nanoscale 5 (17), 7685-7710. doi:10.1039/c3nr01710a

Bixler, G. D., and Bhushan, B. (2014). Rice- and Butterfly-wing Effect Inspired SelfCleaning and Low Drag Micro/nanopatterned Surfaces in Water, Oil, and Air Flow. Nanoscale 6 (1), 76-96. doi:10.1039/c3nr04755e

Bixler, G. D., Theiss, A., Bhushan, B., and Lee, S. C. (2014). Anti-fouling Properties of Microstructured Surfaces Bio-Inspired by Rice Leaves and Butterfly Wings. J. Colloid Interf. Sci. 419, 114-133. doi:10.1016/j.jcis.2013.12.019

Cai, Y., Lin, L., Xue, Z., Liu, M., Wang, S., and Jiang, L. (2014). Filefish-Inspired Surface Design for Anisotropic Underwater Oleophobicity. Adv. Funct. Mater. 24 (6), 809-816. doi:10.1002/adfm.201302034

Callow, J. A., and Callow, M. E. (2011). Trends in the Development of Environmentally Friendly Fouling-Resistant Marine Coatings. Nat. Commun. 2, 244. doi:10.1038/ncomms1251

Carl, C., Poole, A. J., Sexton, B. A., Glenn, F. L., Vucko, M. J., Williams, M. R., et al. (2012). Enhancing the Settlement and Attachment Strength of Pediveligers ofMytilus Galloprovincialisbychanging Surface Wettability and Microtopography. Biofouling 28 (2), 175-186. doi:10.1080/08927014.2012.662676

Carr, L. R., Zhou, Y., Krause, J. E., Xue, H., and Jiang, S. (2011). Uniform Zwitterionic Polymer Hydrogels with a Nonfouling and Functionalizable Crosslinker Using Photopolymerization. Biomaterials 32 (29), 6893-6899. doi:10.1016/j.biomaterials.2011.06.006

\section{FUNDING}

The authors would like to acknowledge the financial support from the National Natural Science Foundation of China (grant numbers 51873240, 51703142), the Sichuan Science and Technology Program (2019YJ0658, 2019YFH0069), the Talent Introduction Program of Chengdu University (2081920001), Sichuan Medical Research Project (S20014), and Chengdu Medical Research Project (2020208).

\section{SUPPLEMENTARY MATERIAL}

The Supplementary Material for this article can be found online at: https://www.frontiersin.org/articles/10.3389/fbioe.2021.807357/ full\#supplementary-material

Cassie, A. B. D., and Baxter, S. (1944). Wettability of Porous Surfaces. Trans. Faraday Soc. 40, 546-551. doi:10.1039/tf9444000546

Chan, H.-M., Erathodiyil, N., Wu, H., Lu, H., Zheng, Y., and Ying, J. Y. (2020). Calcium Cross-Linked Zwitterionic Hydrogels as Antifouling Materials. Mater. Today Commun. 23, 100950. doi:10.1016/j.mtcomm.2020.100950

Chen, D., Wu, M., Li, B., Ren, K., Cheng, Z., Ji, J., et al. (2015). Layer-by-LayerAssembled Healable Antifouling Films. Adv. Mater. 27 (39), 5882-5888. doi:10.1002/adma.201501726

Chen, H., Zhang, M., Yang, J., Zhao, C., Hu, R., Chen, Q., et al. (2014). Synthesis and Characterization of Antifouling poly(N-Acryloylaminoethoxyethanol) with Ultralow Protein Adsorption and Cell Attachment. Langmuir 30 (34), 10398-10409. doi:10.1021/la502136q

Chen, J., Liu, Z., Wen, X., Xu, S., Wang, F., and Pi, P. (2019). Two-Step Approach for Fabrication of Durable Superamphiphobic Fabrics for Self-Cleaning, Antifouling, and On-Demand Oil/Water Separation. Ind. Eng. Chem. Res. 58 (14), 5490-5500. doi:10.1021/acs.iecr.9b00049

Chen, K., Zhou, S., and Wu, L. (2016). Self-Healing Underwater Superoleophobic and Antibiofouling Coatings Based on the Assembly of Hierarchical Microgel Spheres. ACS Nano 10 (1), 1386-1394. doi:10.1021/acsnano.5b06816

Chen, K., Zhou, S., Yang, S., and Wu, L. (2015). Fabrication of All-Water-Based SelfRepairing Superhydrophobic Coatings Based on UV-Responsive Microcapsules. Adv. Funct. Mater. 25 (7), 1035-1041. doi:10.1002/adfm.201403496

Chen, S.-H., Chang, Y., Lee, K.-R., Wei, T.-C., Higuchi, A., Ho, F.-M., et al. (2012). Hemocompatible Control of Sulfobetaine-Grafted Polypropylene Fibrous Membranes in Human Whole Blood via Plasma-Induced Surface Zwitterionization. Langmuir 28 (51), 17733-17742. doi:10.1021/la3036902

Chen, S., Li, L., Zhao, C., and Zheng, J. (2010). Surface Hydration: Principles and Applications Toward Low-Fouling/nonfouling Biomaterials. Polymer 51 (23), 5283-5293. doi:10.1016/j.polymer.2010.08.022

Chen, Z., Du, X.-a., Liu, Y., Ju, Y., Song, S., and Dong, L. (2018). A High-Efficiency Ultrafiltration Nanofibrous Membrane with Remarkable Antifouling and Antibacterial Ability. J. Mater. Chem. A. 6 (31), 15191-15199. doi:10.1039/c8ta02649a

Cheng, W., Yang, C., Ding, X., Engler, A. C., Hedrick, J. L., and Yang, Y. Y. (2015). Broad-Spectrum Antimicrobial/Antifouling Soft Material Coatings Using Poly(ethylenimine) as a Tailorable Scaffold. Biomacromolecules 16 (7), 1967-1977. doi:10.1021/acs.biomac.5b00359

Dobretsov, S., Abed, R. M. M., and Teplitski, M. (2013). Mini-review: Inhibition of Biofouling by Marine Microorganisms. Biofouling 29 (4), 423-441. doi:10.1080/ 08927014.2013.776042

Dobretsov, S., and Thomason, J. C. (2011). The Development of Marine Biofilms on Two Commercial Non-biocidal Coatings: A Comparison Between Silicone and Fluoropolymer Technologies. Biofouling 27 (8), 869-880. doi:10.1080/ 08927014.2011.607233

Du, T., Ma, S., Pei, X., Wang, S., and Zhou, F. (2017). Bio-Inspired Design and Fabrication of Micro/Nano-Brush Dual Structural Surfaces for Switchable Oil Adhesion and Antifouling. Small 13 (4), 1602020. doi:10.1002/smll.201602020

Epstein, A. K., Wong, T.-S., Belisle, R. A., Boggs, E. M., and Aizenberg, J. (2012). Liquid-infused Structured Surfaces with Exceptional Anti-biofouling 
Performance. Proc. Natl. Acad. Sci. 109 (33), 13182-13187. doi:10.1073/ pnas. 1201973109

Erathodiyil, N., Chan, H.-M., Wu, H., and Ying, J. Y. (2020). Zwitterionic Polymers and Hydrogels for Antibiofouling Applications in Implantable Devices. Mater. Today 38, 84-98. doi:10.1016/j.mattod.2020.03.024

Eshet, I., Freger, V., Kasher, R., Herzberg, M., Lei, J., and Ulbricht, M. (2011). Chemical and Physical Factors in Design of Antibiofouling Polymer Coatings. Biomacromolecules 12 (7), 2681-2685. doi:10.1021/bm200476g

Francolini, I., Crisante, F., Martinelli, A., D’llario, L., and Piozzi, A. (2012). Synthesis of Biomimetic Segmented Polyurethanes as Antifouling Biomaterials. Acta Biomater. 8 (2), 549-558. doi:10.1016/j.actbio.2011.10.024

Francolini, I., Donelli, G., Crisante, F., Taresco, V., and Piozzi, A. (2015). "Antimicrobial Polymers for Anti-biofilm Medical Devices: State-Of-Art and Perspectives," in Biofilm-based Healthcare-Associated Infections: Volume II. Editor G. Donelli (New York, NY: Springer International Publishing, Cham), 93-117. doi:10.1007/978-3-319-09782-4_7

Galante, A. J., Haghanifar, S., Romanowski, E. G., Shanks, R. M. Q., and Leu, P. W. (2020). Superhemophobic and Antivirofouling Coating for Mechanically Durable and Wash-Stable Medical Textiles. ACS Appl. Mater. Inter. 12 (19), 22120-22128. doi:10.1021/acsami.9b23058

Gam-Derouich, S., Gosecka, M., Lepinay, S., Turmine, M., Carbonnier, B., Basinska, T., et al. (2011). Highly Hydrophilic Surfaces from Polyglycidol Grafts with Dual Antifouling and Specific Protein Recognition Properties. Langmuir 27 (15), 9285-9294. doi:10.1021/la200290k

Gaw, S. L., Sarkar, S., Nir, S., Schnell, Y., Mandler, D., Xu, Z. J., et al. (2017). Electrochemical Approach for Effective Antifouling and Antimicrobial Surfaces. ACS Appl. Mater. Inter. 9 (31), 26503-26509. doi:10.1021/acsami.7b03761

Grainger, D. W. (1999). The Williams Dictionary of Biomaterials. Mater. Today 2 (3), 29. doi:10.1016/S1369-7021(99)80066-2

Guo, F., Jiao, K., Bai, Y., Guo, J., Chen, Q., Yang, R., et al. (2019). Novel Transcatheter Aortic Heart Valves Exhibiting Excellent Hemodynamic Performance and Low-Fouling Property. J. Mater. Sci. Technol. 35 (1), 207-215. doi:10.1016/j.jmst.2018.09.026

He, H., Xuan, X., Zhang, C., Song, Y., Chen, S., Gong, X., et al. (2019). Simple Thermal Pretreatment Strategy to Tune Mechanical and Antifouling Properties of Zwitterionic Hydrogels. Langmuir 35 (5), 1828-1836. doi:10.1021/acs.langmuir.8b01755

He, M., Gao, K., Zhou, L., Jiao, Z., Wu, M., Cao, J., et al. (2016). Zwitterionic Materials for Antifouling Membrane Surface Construction. Acta Biomater. 40, 142-152. doi:10.1016/j.actbio.2016.03.038

He, Z., Chen, Y., Yang, J., Tang, C., Lv, J., Liu, Y., et al. (2017). Fabrication of Polydimethylsiloxane Films with Special Surface Wettability by 3D Printing. Composites B: Eng. 129, 58-65. doi:10.1016/j.compositesb.2017.07.025

He, Z., Lan, X., Chen, F., Wang, K., Deng, H., Zhang, Q., et al. (2013). Effect of Surface Wettability on Transparency in Different Water Conditions. J. Coat. Technol. Res. 10 (5), 641-647. doi:10.1007/s11998-013-9490-6

He, Z., Lan, X., Hu, Q., Li, H., Li, L., and Mao, J. (2021). Antifouling Strategies Based on Super-phobic Polymer Materials. Prog. Org. Coat. 157, 106285. doi:10.1016/j.porgcoat.2021.106285

He, Z., Ma, M., Lan, X., Chen, F., Wang, K., Deng, H., et al. (2011). Fabrication of a Transparent Superamphiphobic Coating with Improved Stability. Soft Matter 7 (14), 6435-6443. doi:10.1039/c1sm05574g

Hu, P., Xie, Q., Ma, C., and Zhang, G. (2020). Silicone-Based Fouling-Release Coatings for Marine Antifouling. Langmuir 36 (9), 2170-2183. doi:10.1021/acs.langmuir.9b03926

Huang, X.-J., Guduru, D., Xu, Z.-K., Vienken, J., and Groth, T. (2011). Blood Compatibility and Permeability of Heparin-Modified Polysulfone as Potential Membrane for Simultaneous Hemodialysis and LDL Removal. Macromol. Biosci. 11 (1), 131-140. doi:10.1002/mabi.201000278

Ji, H.-F., He, C., Wang, R., Fan, X., Xiong, L., Zhao, W.-F., et al. (2019). Multifunctionalized Polyethersulfone Membranes with Networked Submicrogels to Improve Antifouling Property, Antibacterial Adhesion and Blood Compatibility. Mater. Sci. Eng. C 96, 402-411. doi:10.1016/j.msec.2018.11.047

Jiang, C., Wang, G., Hein, R., Liu, N., Luo, X., and Davis, J. J. (2020). Antifouling Strategies for Selective In Vitro and In Vivo Sensing. Chem. Rev. 120 (8), 3852-3889. doi:10.1021/acs.chemrev.9b00739

Jiang, J., Zhu, L., Zhu, L., Zhang, H., Zhu, B., and Xu, Y. (2013). Antifouling and Antimicrobial Polymer Membranes Based on Bioinspired Polydopamine and Strong Hydrogen-Bonded poly(N-Vinyl Pyrrolidone). ACS Appl. Mater. Inter. 5 (24), 12895-12904. doi:10.1021/am403405c
Jiang, T., Guo, Z., and Liu, W. (2015). Biomimetic Superoleophobic Surfaces: Focusing on Their Fabrication and Applications. J. Mater. Chem. A. 3 (5), 1811-1827. doi:10.1039/C4TA05582A

Jorge, P., Lourenço, A., and Pereira, M. O. (2012). New Trends in Peptide-Based Antibiofilm Strategies: A Review of Recent Achievements and Bioinformatic Approaches. Biofouling 28 (10), 1033-1061. doi:10.1080/08927014.2012.728210

Kambe, Y., Mahara, A., Tanaka, H., Kakinoki, S., Fukazawa, K., Liu, Y., et al. (2019) Short-term Evaluation of Thromboresistance of a Poly(ether Ether Ketone) (PEEK) Mechanical Heart Valve with Poly(2-methacryloyloxyethyl Phosphorylcholine) (PMPC)-grafted Surface in a Porcine Aortic Valve Replacement Model. J. Biomed. Mater. Res. 107 (5), 1052-1063. doi:10.1002/ jbm.a.36628

Kang, S., Lee, M., Kang, M., Noh, M., Jeon, J., Lee, Y., et al. (2016). Development of Anti-biofouling Interface on Hydroxyapatite Surface by Coating Zwitterionic MPC Polymer Containing Calcium-Binding Moieties to Prevent Oral Bacterial Adhesion. Acta Biomater. 40, 70-77. doi:10.1016/j.actbio.2016.03.006

Kang, S. M., Lee, C., Kim, H. N., Lee, B. J., Lee, J. E., Kwak, M. K., et al. (2013). Directional Oil Sliding Surfaces with Hierarchical Anisotropic Groove Microstructures. Adv. Mater. 25 (40), 5756-5761. doi:10.1002/adma.201302083

Keefe, A. J., Brault, N. D., and Jiang, S. (2012). Suppressing Surface Reconstruction of Superhydrophobic PDMS Using a Superhydrophilic Zwitterionic Polymer. Biomacromolecules 13 (5), 1683-1687. doi:10.1021/bm300399s

Kim, S.-E., Zhang, C., Advincula, A. A., Baer, E., and Pokorski, J. K. (2016). Protein and Bacterial Antifouling Behavior of Melt-Coextruded Nanofiber Mats. ACS Appl. Mater. Inter. 8 (14), 8928-8938. doi:10.1021/acsami.6b00093

Krishnan, S., Weinman, C. J., and Ober, C. K. (2008). Advances in Polymers for Anti-biofouling Surfaces. J. Mater. Chem. 18 (29), 3405-3413. doi:10.1039/ B801491D

Kuang, M., Wang, J., and Jiang, L. (2016). Bio-inspired Photonic Crystals with Superwettability. Chem. Soc. Rev. 45 (24), 6833-6854. doi:10.1039/c6cs00562d

Lan, X., Lei, Y., He, Z., Yin, A., Li, L., Tang, Z., et al. (2021). A Transparent Hydrophilic Anti-biofouling Coating for Intraocular Lens Materials Prepared by "bridging" of the Intermediate Adhesive Layer. J. Mater. Chem. B 9 (17), 3696-3704. doi:10.1039/d1tb00065a

Lee, J., and Yong, K. (2015). Combining the Lotus Leaf Effect with Artificial Photosynthesis: Regeneration of Underwater Superhydrophobicity of Hierarchical $\mathrm{ZnO} / \mathrm{Si}$ Surfaces by Solar Water Splitting. NPG Asia Mater. 7 (7), e201. doi:10.1038/am.2015.74

Lee, S. G., Lim, H. S., Lee, D. Y., Kwak, D., and Cho, K. (2013). Tunable Anisotropic Wettability of Rice Leaf-like Wavy Surfaces. Adv. Funct. Mater. 23 (5), 547-553. doi:10.1002/adfm.201201541

Lei, Y., Lan, X., He, Z., Yin, A., Jin, W., Hu, Q., et al. (2021). Multifarious Antibiofouling Bioprosthetic Heart Valve Materials with the Formation of Interpenetrating Polymer Network Structures. Mater. Des. 206, 109803. doi:10.1016/j.matdes.2021.109803

Lejars, M., Margaillan, A., and Bressy, C. (2012). Fouling Release Coatings: A Nontoxic Alternative to Biocidal Antifouling Coatings. Chem. Rev. 112 (8), 4347-4390. doi:10.1021/cr200350v

Leslie, D. C., Waterhouse, A., Berthet, J. B., Valentin, T. M., Watters, A. L., Jain, A., et al. (2014). A Bioinspired Omniphobic Surface Coating on Medical Devices Prevents Thrombosis and Biofouling. Nat. Biotechnol. 32, 1134-1140. doi:10.1038/nbt.3020

Li, D., Fan, Y., Han, G., and Guo, Z. (2020). Superomniphobic Silk Fibroin/Ag Nanowires Membrane for Flexible and Transparent Electronic Sensor. ACS Appl. Mater. Inter. 12 (8), 10039-10049. doi:10.1021/acsami.9b23378

Li, M., Schlaich, C., Willem Kulka, M., Donskyi, I. S., Schwerdtle, T., Unger, W. E. S., et al. (2019). Mussel-inspired Coatings with Tunable Wettability, for Enhanced Antibacterial Efficiency and Reduced Bacterial Adhesion. J. Mater. Chem. B 7 (21), 3438-3445. doi:10.1039/C9TB00534J

Li, Q., Lin, H.-H., and Wang, X.-L. (2014). Preparation of Sulfobetaine-Grafted PVDF Hollow Fiber Membranes with a Stably Anti-protein-fouling Performance. Membranes 4 (2), 181-199. doi:10.3390/membranes4020181

Li, X., Hu, X., and Cai, T. (2017). Construction of Hierarchical Fouling Resistance Surfaces onto Poly(vinylidene Fluoride) Membranes for Combating Membrane Biofouling. Langmuir 33 (18), 4477-4489. doi:10.1021/acs.langmuir.7b00191

Li, X., Zhao, S., Hu, W., Zhang, X., Pei, L., and Wang, Z. (2019). Robust Superhydrophobic Surface with Excellent Adhesive Properties Based on Benzoxazine/epoxy/mesoporous SiO2. Appl. Surf. Sci. 481, 374-378. doi:10.1016/j.apsusc.2019.03.114 
Liang, Y., Kim, S., Yang, E., and Choi, H. (2020). Omni-Directional Protected Nanofiber Membranes by Surface Segregation of PDMS-Terminated Triblock Copolymer for High-Efficiency Oil/Water Emulsion Separation. ACS Appl. Mater. Inter. 12 (22), 25324-25333. doi:10.1021/acsami.0c05559

Liu, G., Li, K., Wang, H., Ma, L., Yu, L., and Nie, Y. (2020). Stable Fabrication of Zwitterionic Coating Based on Copper-Phenolic Networks on Contact Lens with Improved Surface Wettability and Broad-Spectrum Antimicrobial Activity. ACS Appl. Mater. Inter. 12 (14), 16125-16136. doi:10.1021/acsami.0c02143

Liu, S., and Guo, W. (2018). Anti-Biofouling and Healable Materials: Preparation, Mechanisms, and Biomedical Applications. Adv. Funct. Mater. 28 (41), 1800596. doi:10.1002/adfm.201800596

Liu, S., Zheng, J., Hao, L., Yegin, Y., Bae, M., Ulugun, B., et al. (2020). DualFunctional, Superhydrophobic Coatings with Bacterial Anticontact and Antimicrobial Characteristics. ACS Appl. Mater. Inter. 12 (19), 21311-21321. doi:10.1021/acsami.9b18928

Liu, X., Tong, W., Wu, Z., and Jiang, W. (2013). Poly(N-vinylpyrrolidone)-grafted Poly(dimethylsiloxane) Surfaces with Tunable Microtopography and Antibiofouling Properties. RSC Adv. 3 (14), 4716-4722. doi:10.1039/C3RA23069D

Liu, Y., Zhang, D., Ren, B., Gong, X., Liu, A., Chang, Y., et al. (2020). Computational Investigation of Antifouling Property of Polyacrylamide Brushes. Langmuir 36 (11), 2757-2766. doi:10.1021/acs.langmuir.0c00165

Maan, A. M. C., Hofman, A. H., Vos, W. M., and Kamperman, M. (2020). Recent Developments and Practical Feasibility of Polymer-Based Antifouling Coatings. Adv. Funct. Mater. 30 (32), 2000936. doi:10.1002/adfm.202000936

Magin, C. M., Cooper, S. P., and Brennan, A. B. (2010). Non-toxic Antifouling Strategies. Mater. Today 13 (4), 36-44. doi:10.1016/s1369-7021(10)70058-4

Martin, S., and Bhushan, B. (2017). Transparent, Wear-Resistant, Superhydrophobic and Superoleophobic Poly(dimethylsiloxane) (PDMS) Surfaces. J. Colloid Interf. Sci. 488, 118-126. doi:10.1016/j.jcis.2016.10.094

Martin, S., Brown, P. S., and Bhushan, B. (2017). Fabrication Techniques for Bioinspired, Mechanically-Durable, Superliquiphobic Surfaces for Water, Oil, and Surfactant Repellency. Adv. Colloid Interf. Sci. 241, 1-23. doi:10.1016/ j.cis.2017.01.004

Martínez-Gómez, A., Alvarez, C., de Abajo, J., del Campo, A., Cortajarena, A. L., and Rodriguez-Hernandez, J. (2015). Poly(ethylene Oxide) Functionalized Polyimide-Based Microporous Films to Prevent Bacterial Adhesion. ACS Appl. Mater. Inter. 7 (18), 9716-9724. doi:10.1021/acsami.5b01525

Mazinani, S., Al-Shimmery, A., Chew, Y. M. J., and Mattia, D. (2019). 3D Printed Fouling-Resistant Composite Membranes. ACS Appl. Mater. Inter. 11 (29), 26373-26383. doi:10.1021/acsami.9b07764

Mieszkin, S., Callow, M. E., and Callow, J. A. (2013). Interactions Between Microbial Biofilms and Marine Fouling Algae: A Mini Review. Biofouling 29 (9), 1097-1113. doi:10.1080/08927014.2013.828712

Mohan, T., Kargl, R., Tradt, K. E., Kulterer, M. R., Braćić, M., Hribernik, S., et al. (2015). Antifouling Coating of Cellulose Acetate Thin Films with Polysaccharide Multilayers. Carbohydr. Polym. 116, 149-158. doi:10.1016/ j.carbpol.2014.04.068

Movafaghi, S., Leszczak, V., Wang, W., Sorkin, J. A., Dasi, L. P., Popat, K. C., et al. (2017). Hemocompatibility of Superhemophobic Titania Surfaces. Adv. Healthc. Mater. 6 (4), 1600717. doi:10.1002/adhm.201600717

Pan, S., Guo, R., Richardson, J. J., Berry, J. D., Besford, Q. A., Björnmalm, M., et al. (2019). Ricocheting Droplets Moving on Super-Repellent Surfaces. Adv. Sci. 6 (21), 1901846. doi:10.1002/advs.201901846

Pu, X., Li, G., and Huang, H. (2016). Preparation, Anti-biofouling and DragReduction Properties of a Biomimetic Shark Skin Surface. Biol. Open 5 (4), 389-396. doi:10.1242/bio.016899

Ran, F., Nie, S., Zhao, W., Li, J., Su, B., Sun, S., et al. (2011). Biocompatibility of Modified Polyethersulfone Membranes by Blending an Amphiphilic Triblock Co-polymer of Poly(vinyl Pyrrolidone)-B-Poly(methyl Methacrylate)-BPoly(vinyl Pyrrolidone). Acta Biomater. 7 (9), 3370-3381. doi:10.1016/ j.actbio.2011.05.026

Roach, P., Shirtcliffe, N. J., and Newton, M. I. (2008). Progess in Superhydrophobic Surface Development. Soft Matter 4 (2), 224-240. doi:10.1039/b712575p

Rosenhahn, A., Schilp, S., Kreuzer, H. J., and Grunze, M. (2010). The Role of "inert" Surface Chemistry in Marine Biofouling Prevention. Phys. Chem. Chem. Phys. 12 (17), 4275-4286. doi:10.1039/c001968m

Santiago, A., Irusta, L., Schäfer, T., Corres, A., Martin, L., and González, A. (2016). Resistance to Protein Sorption as a Model of Antifouling Performance of
Poly(siloxane-Urethane) Coatings Exhibiting Phase Separated Morphologies. Prog. Org. Coat. 99, 110-116. doi:10.1016/j.porgcoat.2016.05.011

Scardino, A. J., and de Nys, R. (2011). Mini Review: Biomimetic Models and Bioinspired Surfaces for Fouling Control. Biofouling 27 (1), 73-86. doi:10.1080/ 08927014.2010 .536837

Seo, J.-H., Shibayama, T., Takai, M., and Ishihara, K. (2011). Quick and Simple Modification of a Poly(dimethylsiloxane) Surface by Optimized Molecular Design of the Anti-biofouling Phospholipid Copolymer. Soft Matter 7 (6), 2968-2976. doi:10.1039/COSM01292K

Shi, X., Dou, R., Ma, T., Liu, W., Lu, X., Shea, K. J., et al. (2015). Bioinspired Lotuslike Self-Illuminous Coating. ACS Appl. Mater. Inter. 7 (33), 18424-18428. doi:10.1021/acsami.5b04499

Siddiquie, R. Y., Agrawal, A., and Joshi, S. S. (2020). Surface Alterations to Impart Antiviral Properties to Combat COVID-19 Transmission. Trans. Indian Natl. Acad. Eng. 5 (2), 343-347. doi:10.1007/s41403-020-00096-9

Siddiquie, R. Y., Gaddam, A., Agrawal, A., Dimov, S. S., and Joshi, S. S. (2020). Anti-Biofouling Properties of Femtosecond Laser-Induced Submicron Topographies on Elastomeric Surfaces. Langmuir 36 (19), 5349-5358. doi:10.1021/acs.langmuir.0c00753

Simovich, T., Rosenhahn, A., and Lamb, R. N. (2020). Thermoregeneration of Plastrons on Superhydrophobic Coatings for Sustained Antifouling Properties. Adv. Eng. Mater. 22 (3), 1900806. doi:10.1002/adem.201900806

Sin, M.-C., Sun, Y.-M., and Chang, Y. (2014). Zwitterionic-based Stainless Steel with Well-Defined Polysulfobetaine Brushes for General Bioadhesive Control. ACS Appl. Mater. Inter. 6 (2), 861-873. doi:10.1021/am4041256

Stirpe, M., Brugnoli, B., Donelli, G., Francolini, I., and Vuotto, C. (2020). Poloxamer 338 Affects Cell Adhesion and Biofilm Formation in Escherichia coli: Potential Applications in the Management of Catheter-Associated Urinary Tract Infections. Pathogens 9 (11), 885. doi:10.3390/pathogens9110885

$\mathrm{Su}, \mathrm{B}$., Tian, Y., and Jiang, L. (2016). Bioinspired Interfaces with Superwettability: From Materials to Chemistry. J. Am. Chem. Soc. 138 (6), 1727-1748. doi:10.1021/jacs.5b12728

Su, M., Liu, Y., Zhang, Y., Wang, Z., Li, Y., and He, P. (2018). Robust and Underwater Superoleophobic Coating with Excellent Corrosion and Biofouling Resistance in Harsh Environments. Appl. Surf. Sci. 436, 152-161. doi:10.1016/ j.apsusc.2017.11.215

Su, X., Hao, D., Xu, X., Guo, X., Li, Z., and Jiang, L. (2020). Hydrophilic/Hydrophobic Heterogeneity Anti-biofouling Hydrogels with Well-Regulated Rehydration. ACS Appl. Mater. Inter. 12 (22), 25316-25323. doi:10.1021/acsami.0c05406

Telford, A. M., James, M., Meagher, L., and Neto, C. (2010). Thermally CrossLinked PNVP Films as Antifouling Coatings for Biomedical Applications. ACS Appl. Mater. Inter. 2 (8), 2399-2408. doi:10.1021/am100406j

Tian, Y., Su, B., and Jiang, L. (2014). Interfacial Material System Exhibiting Superwettability. Adv. Mater. 26 (40), 6872-6897. doi:10.1002/adma.201400883

Valencia, L., Kumar, S., Jalvo, B., Mautner, A., Salazar-Alvarez, G., and Mathew, A. P. (2018). Fully Bio-Based Zwitterionic Membranes with Superior Antifouling and Antibacterial Properties Prepared via Surface-Initiated Free-Radical Polymerization of Poly(cysteine Methacrylate). J. Mater. Chem. A. 6 (34), 16361-16370. doi:10.1039/c8ta06095a

Wang, B., Ye, Z., Tang, Y., Han, Y., Lin, Q., Liu, H., et al. (2016). Fabrication of Nonfouling, Bactericidal, and Bacteria Corpse Release Multifunctional Surface Through Surface-Initiated RAFT Polymerization. Ijn Vol. 12, 111-125. doi:10.2147/ijn.S107472

Wang, H., Jasensky, J., Ulrich, N. W., Cheng, J., Huang, H., Chen, Z., et al. (2017). Capsaicin-Inspired Thiol-Ene Terpolymer Networks Designed for Antibiofouling Coatings. Langmuir 33 (47), 13689-13698. doi:10.1021/acs.langmuir.7b03098

Wang, H., Wu, Y., Cui, C., Yang, J., and Liu, W. (2018). Antifouling Super Water Absorbent Supramolecular Polymer Hydrogel as an Artificial Vitreous Body. Adv. Sci. 5 (11), 1800711. doi:10.1002/advs.201800711

Wang, J., and He, C. (2019). Photopolymerized Biomimetic Self-Adhesive Polydimethylsiloxane-Based Amphiphilic Cross-Linked Coating for Antibiofouling. Appl. Surf. Sci. 463, 1097-1106. doi:10.1016/j.apsusc.2018.08.214

Wang, L., Chen, X., Cao, X., Xu, J., Zuo, B., Zhang, L., et al. (2015). Fabrication of Polymer brush Surfaces with Highly-Ordered Perfluoroalkyl Side Groups at the Brush End and Their Antibiofouling Properties. J. Mater. Chem. B 3 (21), 4388-4400. doi:10.1039/C5TB00210A

Wang, X., Liu, X., Zhou, F., and Liu, W. (2011). Self-healing Superamphiphobicity. Chem. Commun. 47 (8), 2324-2326. doi:10.1039/c0cc04066e 
Wang, Z., Scheres, L., Xia, H., and Zuilhof, H. (2020). Developments and Challenges in Self-Healing Antifouling Materials. Adv. Funct. Mater. 30 (26), 1908098. doi:10.1002/adfm.201908098

Wenzel, R. N. (1936). Resistance of Solid Surfaces to Wetting by Water. Ind. Eng. Chem. 28, 988-994. doi:10.1021/ie50320a024

Wu, D., Wang, J.-N., Wu, S.-Z., Chen, Q.-D., Zhao, S., Zhang, H., et al. (2011). Three-Level Biomimetic Rice-Leaf Surfaces with Controllable Anisotropic Sliding. Adv. Funct. Mater. 21 (15), 2927-2932. doi:10.1002/adfm.201002733

Wu, J.-G., Chen, J.-H., Liu, K.-T., and Luo, S.-C. (2019). Engineering Antifouling Conducting Polymers for Modern Biomedical Applications. ACS Appl. Mater. Inter. 11 (24), 21294-21307. doi:10.1021/acsami.9b04924

Wu, Z., Tong, W., Jiang, W., Liu, X., Wang, Y., and Chen, H. (2012). Poly(N-vinylpyrrolidone)-modified Poly(dimethylsiloxane) Elastomers as Anti-biofouling Materials. Colloids Surf. B: Biointerfaces 96, 37-43. doi:10.1016/j.colsurfb.2012.03.016

Xia, F., and Jiang, L. (2008). Bio-inspired, Smart, Multiscale Interfacial Materials. Adv. Mater. 20 (15), 2842-2858. doi:10.1002/adma.200800836

Xia, Y., Adibnia, V., Huang, R., Murschel, F., Faivre, J., Xie, G., et al. (2019). Biomimetic Bottlebrush Polymer Coatings for Fabrication of Ultralow Fouling Surfaces. Angew. Chem. Int. Ed. 58 (5), 1308-1314. doi:10.1002/anie.201808987

Xie, Q., Xie, Q., Pan, J., Ma, C., and Zhang, G. (2018). Biodegradable Polymer with Hydrolysis-Induced Zwitterions for Antibiofouling. ACS Appl. Mater. Inter. 10 (13), 11213-11220. doi:10.1021/acsami.8b00962

Xie, Y., Li, S.-S., Jiang, X., Xiang, T., Wang, R., and Zhao, C.-S. (2015). Zwitterionic Glycosyl Modified Polyethersulfone Membranes with Enhanced Anti-fouling Property and Blood Compatibility. J. Colloid Interf. Sci. 443, 36-44. doi:10.1016/ j.jcis.2014.11.053

Xu, T., Yang, J., Zhang, J., Zhu, Y., Li, Q., Pan, C., et al. (2017). Facile Modification of Electrospun Fibrous Structures with Antifouling Zwitterionic Hydrogels. Biomed. Mater. 13 (1), 015021. doi:10.1088/1748-605X/aa89b2

Yang, H., Chang, H., Zhang, Q., Song, Y., Jiang, L., Jiang, Q., et al. (2020). Highly Branched Copolymers with Degradable Bridges for Antifouling Coatings. ACS Appl. Mater. Inter. 12 (14), 16849-16855. doi:10.1021/acsami.9b22748

Ye, Q., He, B., Zhang, Y., Zhang, J., Liu, S., and Zhou, F. (2019). Grafting Robust Thick Zwitterionic Polymer Brushes via Subsurface-Initiated Ring-Opening Metathesis Polymerization for Antimicrobial and Anti-biofouling. ACS Appl. Mater. Inter. 11 (42), 39171-39178. doi:10.1021/acsami.9b11946

Yebra, D. M., Kiil, S., and Dam-Johansen, K. (2004). Antifouling Technology-Past, Present and Future Steps Towards Efficient and Environmentally Friendly Antifouling Coatings. Prog. Org. Coat. 50 (2), 75-104. doi:10.1016/ j.porgcoat.2003.06.001

Yeh, S.-B., Chen, C.-S., Chen, W.-Y., and Huang, C.-J. (2014). Modification of Silicone Elastomer with Zwitterionic Silane for Durable Antifouling Properties. Langmuir 30 (38), 11386-11393. doi:10.1021/la502486e

Yin, Z., Cheng, C., Qin, H., Nie, C., He, C., and Zhao, C. (2015). Hemocompatible Polyethersulfone/polyurethane Composite Membrane for High-Performance Antifouling and Antithrombotic Dialyzer. J. Biomed. Mater. Res. 103 (1), 97-105. doi:10.1002/jbm.b.33177

Young, T. (1805). III. An Essay on the Cohesion of Fluids. Phil. Trans. R. Soc. 95 (0), 65-87. doi:10.1098/rstl.1805.0005

Yu, H., Cao, Y., Kang, G., Liu, J., Li, M., and Yuan, Q. (2009). Enhancing Antifouling Property of Polysulfone Ultrafiltration Membrane by Grafting Zwitterionic Copolymer via UV-Initiated Polymerization. J. Membr. Sci. 342 (1-2), 6-13. doi:10.1016/j.memsci.2009.05.041

Yu, S., Guo, Z., and Liu, W. (2015). Biomimetic Transparent and Superhydrophobic Coatings: From Nature and Beyond Nature. Chem. Commun. 51 (10), 1775-1794. doi:10.1039/C4CC06868H

Yu, Y., Shao, H., He, Z., Tang, C., Yang, J., Li, Y., et al. (2018). Patternable Poly(chloro-P-Xylylene) Film with Tunable Surface Wettability Prepared by Temperature and Humidity Treatment on a Polydimethylsiloxane/Silica Coating. Materials 11 (4), 486. doi:10.3390/ma11040486

Zarghami, S., Mohammadi, T., Sadrzadeh, M., and Van der Bruggen, B. (2019). Superhydrophilic and Underwater Superoleophobic Membranes - A Review of Synthesis Methods. Prog. Polym. Sci. 98, 101166. doi:10.1016/ j.progpolymsci.2019.101166

Zhang, D., Ren, B., Zhang, Y., Liu, Y., Chen, H., Xiao, S., et al. (2020). Micro- and Macroscopically Structured Zwitterionic Polymers with Ultralow Fouling Property. J. Colloid Interf. Sci. 578, 242-253. doi:10.1016/j.jcis.2020.05.122
Zhang, H., and Chiao, M. (2015). Anti-fouling Coatings of Poly(dimethylsiloxane) Devices for Biological and Biomedical Applications. J. Med. Biol. Eng. 35 (2), 143-155. doi:10.1007/s40846-015-0029-4

Zhang, J., Chen, L., Chen, L., Qian, S., Mou, X., and Feng, J. (2021). Highly Antifouling, Biocompatible and Tough Double Network Hydrogel Based on Carboxybetaine-type Zwitterionic Polymer and Alginate. Carbohydr. Polym. 257, 117627. doi:10.1016/j.carbpol.2021.117627

Zhang, J., Qian, S., Chen, L., Chen, L., Zhao, L., and Feng, J. (2021). Highly Antifouling Double Network Hydrogel Based on Poly(sulfobetaine Methacrylate) and Sodium Alginate with Great Toughness. J. Mater. Sci. Technol. 85, 235-244. doi:10.1016/j.jmst.2021.01.012

Zhang, J., Wang, G., Zhang, J., Xu, Z., Zhao, Y., Wang, Y., et al. (2021). SubstrateIndependent, Regenerable Anti-biofouling Coating for Polymeric Membranes. Membranes 11 (3), 205. doi:10.3390/membranes11030205

Zhang, P., Lin, L., Zang, D., Guo, X., and Liu, M. (2016). Designing Bioinspired Anti-biofouling Surfaces Based on a Superwettability Strategy. Small 13 (4), 1503334. doi:10.1002/smll.201503334

Zhao, X., and Liu, C. (2016). One-step Fabricated Bionic PVDF Ultrafiltration Membranes Exhibiting Innovative Antifouling Ability to the Cake Fouling. J. Membr. Sci. 515, 29-35. doi:10.1016/j.memsci.2016.05.025

Zheng, J., Song, W., Huang, H., and Chen, H. (2010). Protein Adsorption and Cell Adhesion on Polyurethane/Pluronic Surface with Lotus Leaf-like Topography. Colloids Surf. B: Biointerfaces 77 (2), 234-239. doi:10.1016/j.colsurfb.2010.01.032

Zheng, S., Bawazir, M., Dhall, A., Kim, H.-E., He, L., Heo, J., et al. (2021). Implication of Surface Properties, Bacterial Motility, and Hydrodynamic Conditions on Bacterial Surface Sensing and Their Initial Adhesion. Front. Bioeng. Biotechnol. 9 (82), 643722. doi:10.3389/fbioe.2021.643722

Zhou, J., Lin, Y., Wang, L., Zhou, L., Yu, B., Zou, X., et al. (2021). Poly(carboxybetaine Methacrylate) Grafted on PVA Hydrogel via a Novel Surface Modification Method Under Near-Infrared Light for Enhancement of Antifouling Properties. Colloids Surf. A: Physicochemical Eng. Aspects 617, 126369. doi:10.1016/j.colsurfa.2021.126369

Zhu, D., Li, X., Zhang, G., Zhang, X., Zhang, X., Wang, T., et al. (2010). Mimicking the Rice Leaf-From Ordered Binary Structures to Anisotropic Wettability. Langmuir 26 (17), 14276-14283. doi:10.1021/la102243c

Zhu, H., Hu, W., Xu, Y., Wang, B., Zheng, D., Fu, Y., et al. (2019). Gradient Structure Based Dual-Robust Superhydrophobic Surfaces with HighAdhesive Force. Appl. Surf. Sci. 463, 427-434. doi:10.1016/ j.apsusc.2018.08.241

Zhu, L., Liu, F., Yu, X., and Xue, L. (2015). Poly(Lactic Acid) Hemodialysis Membranes with Poly(Lactic Acid)-Block-Poly(2-Hydroxyethyl Methacrylate) Copolymer as Additive: Preparation, Characterization, and Performance. ACS Appl. Mater. Inter. 7 (32), 17748-17755. doi:10.1021/acsami.5b03951

Zhu, L., Song, H., Wang, J., and Xue, L. (2017). Polysulfone Hemodiafiltration Membranes with Enhanced Anti-fouling and Hemocompatibility Modified by Poly(vinyl Pyrrolidone) via In Situ Cross-Linked Polymerization. Mater. Sci. Eng. C 74, 159-166. doi:10.1016/j.msec.2017.02.019

Zhu, X., Zhang, Z., Ren, G., Yang, J., Wang, K., Xu, X., et al. (2012). A Novel Superhydrophobic Bulk Material. J. Mater. Chem. 22 (38), 20146-20148. doi:10.1039/C2JM33769J

Conflict of Interest: The authors declare that the research was conducted in the absence of any commercial or financial relationships that could be construed as a potential conflict of interest.

Publisher's Note: All claims expressed in this article are solely those of the authors and do not necessarily represent those of their affiliated organizations, or those of the publisher, the editors and the reviewers. Any product that may be evaluated in this article, or claim that may be made by its manufacturer, is not guaranteed or endorsed by the publisher.

Copyright (C) 2021 He, Yang, Wang, Mu, Pan, Lan, Li and Deng. This is an openaccess article distributed under the terms of the Creative Commons Attribution License (CC BY). The use, distribution or reproduction in other forums is permitted, provided the original author(s) and the copyright owner(s) are credited and that the original publication in this journal is cited, in accordance with accepted academic practice. No use, distribution or reproduction is permitted which does not comply with these terms. 